\title{
Planning and implementing an essential package of sexual and reproductive health services: Guidance for integrating family planning and STI/RTI with other reproductive health and primary health services
}

Katherine Williams

Population Council

Charlotte E. Warren

Population Council

Ian Askew

Population Council

Follow this and additional works at: https://knowledgecommons.popcouncil.org/departments_sbsr-rh

Part of the Demography, Population, and Ecology Commons, Family, Life Course, and Society Commons, Gender and Sexuality Commons, International Public Health Commons, Maternal and Child Health Commons, Medicine and Health Commons, and the Women's Health Commons How does access to this work benefit you? Let us know!

\section{Recommended Citation}

Williams, Katherine, Charlotte E. Warren, and lan Askew. 2010. "Planning and implementing an essential package of sexual and reproductive health services: Guidance for integrating family planning and STI/RTI with other reproductive health and primary health services." Washington, DC: Population Council. 

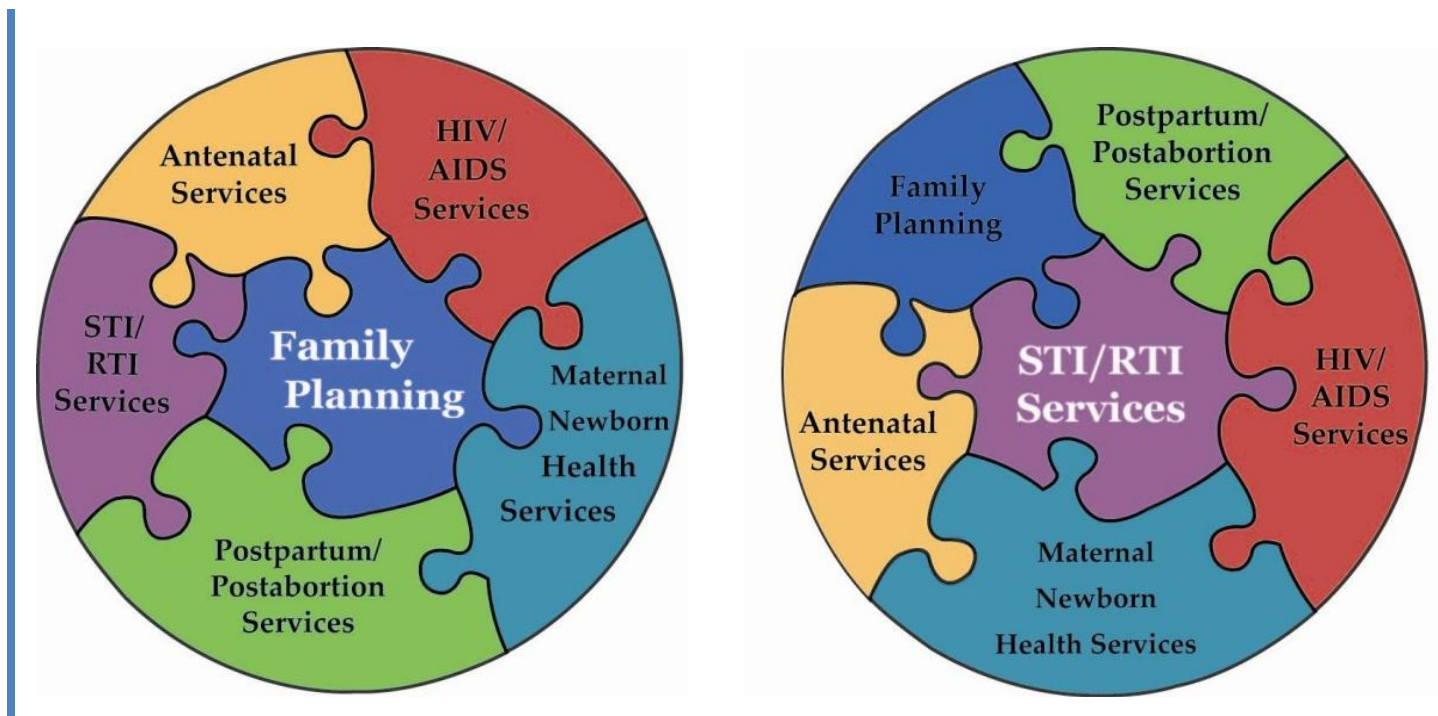

\section{Planning and Implementing}

\section{an Essential Package of Sexual and Reproductive Health Services}

Guidance for Integrating Family Planning and STI/RTI with other Reproductive Health and Primary Health Services

Katherine Williams, Charlotte Warren, and Ian Askew October 2010 


\section{(1) Population Council}

The Population Council conducts research worldwide to improve policies, programs, and products in three areas: HIV and AIDS; Poverty, Gender, and Youth; and Reproductive Health.

Published in October 2010.

(C) 2010 The Population Council, Inc.

Population Council

4301 Connecticut Ave NW

Suite 280

Washington, DC 20009

Telephone: +12023399400

Facsimile: +1202 2378410

www.popcouncil.org

Any part of this publication may be reproduced without permission for limited distribution provided it is distributed without charge and the Population Council is acknowledged as its source. The Population Council would appreciate receiving a copy of any materials in which the text is used.

Suggested citation: Williams, Katherine, Charlotte Warren, and Ian Askew. 2010. "Planning and implementing an essential package of sexual and reproductive health services: Guidance for integrating family planning and STI/RTI with other reproductive health and primary health services." Washington, DC: Population Council. 


\section{Acknowledgements}

The authors would like to thank the following individuals, for sharing their professional insights and expertise in the fields of sexual and reproductive health and service integration: Nahla AbdelTawab, Meiwita Budiharsana, Fernando Gonzales Salguero, ME Khan, Wilson Liambila, Charity Ndigwa, Mantshi Teffo-Menziwa, and Ubaidur Rob. We would also like to thank Nuriye Ortayli and Juncal Plazaola-Castano for their invaluable help and feedback during the compilation of this document. Lastly, we thank John Townsend for his guidance in the realization of the "How To" tools as well as his editorial support.

This document is made possible by the generous support of the United Nations Population Fund under the terms of two Agreements: Challenges to provision of quality family planning services analyzed (Grant Number GRP6R32A) and Models for scale-up of essential SRH package available and disseminated (Grant Number GRP6R12A). The contents are the responsibility of the Population Council and do not necessarily reflect the views of UNFPA. 


\section{Table of Contents}

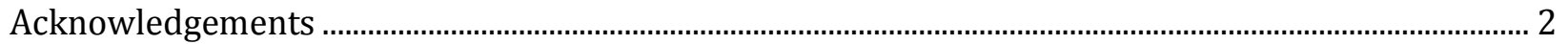

Purpose and Organization of Document

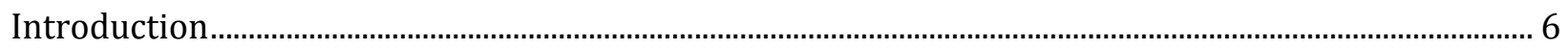

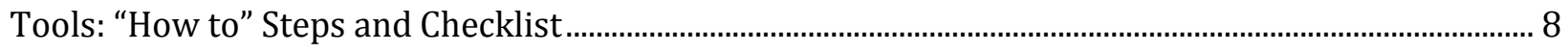

Steps for Planning and Implementing an Essential_Package of SRH Services ..............................10

The Checklist for Planning and Implementing an Essential_Package of SRH Services..............11

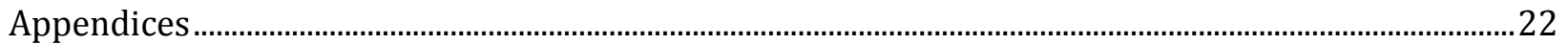




\section{Purpose and Organization of Document}

The second goal of UNFPA's 2008-2011 Strategic Plan is "Universal access to reproductive health by 2015 and universal access to comprehensive HIV prevention by 2010 for improved quality of life." To achieve this goal, UNFPA has identified a number of outcomes that will contribute to achieving this goal:
"Reproductive rights and [sexual and reproductive health] SRH demand promoted and the essential SRH package, including reproductive health commodities and human resources for health, integrated in public policies of development and humanitarian frameworks with strengthened implementation monitoring", which includes a key global / regional output of Models for scale-up of essential SRH package made available and disseminated.
"Access to and utilization of quality family planning services by individuals and couples increased according to reproductive intention", which includes the output of Challenges to provision of quality family planning services analyzed.

Through an extensive search of the published literature and collation of unpublished literature on programmatic experiences with developing and implementing integrated packages of SRH services, the Population Council gathered a body of evidence from which this guidance for UNFPA staff and national counterparts has been developed. Although the steps recommended for developing an essential SRH package are intended to provide a framework for developing any essential SRH package, UNFPA identified two priority areas to serve as examples for this guidance: 1) integrating family planning into maternal and newborn care services, and 2) integrating services for preventing and managing sexually transmitted infections (STIs) / reproductive tract infections (RTIs) into primary health care services.

This guidance document comprises three sections. The Introduction explains and justifies why the development and implementation of an essential SRH package should be planned and framed within the World Health Organization's (WHO) six Building Blocks of Health Systems. The second section presents the "How To" steps and checklist tools for planning, implementing and scaling up an essential SRH package, including specific examples for the two priority areas indicated above. The third section provides the evidence-base supporting the recommendations and action-points proposed in each tool. This evidence-base includes key findings and summary recommendations from the literature review (in matrix format) and a bibliography of the references included in the literature review. 


\section{Introduction}

Because of limited human, financial and infrastructure resources, many developing countries are only able to offer a core package of basic SRH services, usually focused around maternal, newborn and child health, including family planning. As countries expand their vision of addressing peoples' rights to a full and comprehensive range of SRH services, while streamlining the management of SRH services, UNFPA recommends that SRH services should be integrated within the primary health care system, with referrals for more specialized needs. Furthermore, to reflect the Plan of Action proposed at the International Conference on Population and Development (ICPD) in 1994 and to accelerate progress towards all three health millennium development goals, UNFPA suggests that a full SRH package delivered through primary health care with referrals would include:

- Family planning/birth spacing services

- Antenatal care, skilled attendance at delivery, and postnatal care

- Management of obstetric and neonatal complications and emergencies

- Prevention of abortion and management of complications resulting from unsafe abortion

- Prevention and treatment of reproductive tract infections and sexually transmitted infections including HIV/AIDS

- Early diagnosis and treatment for breast and cervical cancer

- Promotion, education and support for exclusive breast feeding

- Prevention and appropriate treatment of sub-fertility and infertility

- Active discouragement of harmful practices such as female genital cutting

- Adolescent sexual and reproductive health

- Prevention and management of gender-based violence.

While this full package of SRH services can, and should, be available only through an extensive series of referrals for most developing countries, many countries are now seeking to develop essential packages of SRH services that meet the most pressing needs and are most likely to accelerate progress towards the health millennium development goals. Each country's essential SRH package will be determined and defined by the particular SRH needs of its population, with particular attention to the most vulnerable and marginalized populations. Central to every essential package, is the need to organize service delivery so as to maximize the integration of complementary services that can be delivered effectively, safely and with cost-efficiencies over the delivery of individual services, and in combinations that are both acceptable to the client and feasible to the health system, and especially the provider. 
For countries seeking to develop and offer an essential SRH package, regardless of the composition of its component services, it is critical that planning, introduction and expansion of the package be undertaken within the broad framework of strengthening the overall primary health care system. Consequently, the guidance provided in this document is based upon the six interlinked "building blocks for health systems" as defined by WHO (2007a) so that the following components are strengthened:

Service Delivery: to deliver effective, safe and quality interventions for improving SRH status among those most in need in an acceptable and efficient manner;

Human Resources: to perform responsively, fairly and efficiently to achieve the best health outcomes given resources and circumstances;

Health Information: to produce, analyze, communicate and use reliable and timely information on health system performance, as well as health determinants and status;

Medicines and Technologies: to ensure equitable access to products and technologies that are of assured quality, safety, efficacy and cost-effectiveness;

Health Financing: to raise adequate funds so that people can use needed services and are protected from impoverishment through having to pay for them, as well as providing incentives for providers to perform efficiently.

Leadership and Governance: to ensure a strategic policy framework exists, together with effective oversight and accountability;

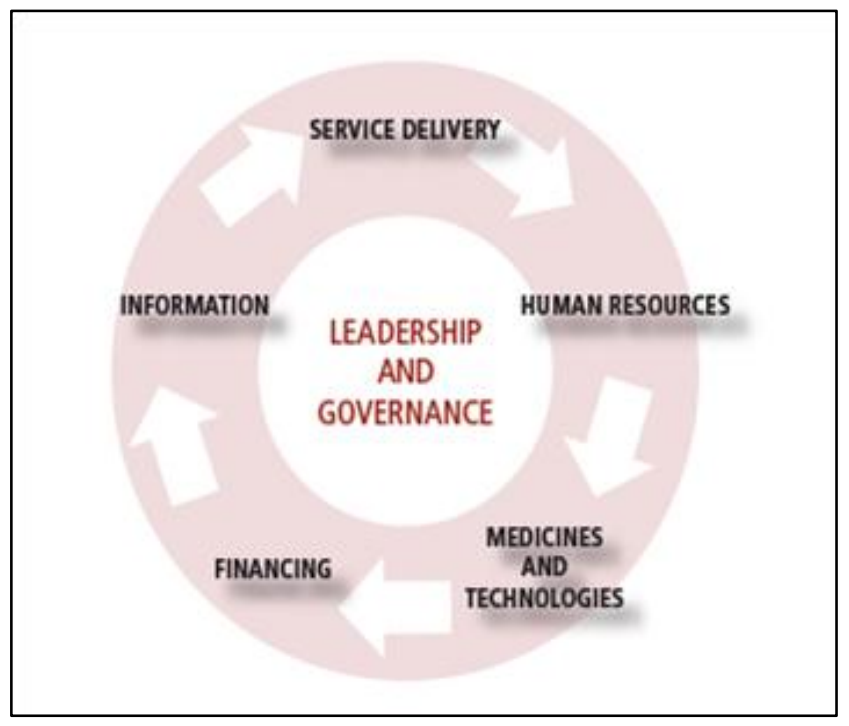




\section{Tools: "How to" Steps and Checklist}

The Steps for Planning and Implementing an Essential Package of SRH services provides a five-step guide to lead UNFPA Program Officers and national partners through a process of developing, implementing and expanding an essential package of SRH services. The five steps are organized chronologically, yet several actions within each broad step overlap in time and may also be revisited over time. Countries and program areas experience different issues related to SRH services and are at different stages of development, therefore the use and chosen starting-point should be country-specific. The five steps include 1) Prepare; 2) Assess and Analyze; Identify Facilities for Initial Program/Phase Implementation; 3) Define and Operationalize the Essential SRH Package; 4) Assess the Initial Phase and Plan for Expansion; and 5) Maintain Commitment and Sustain.

The Steps are presented in two formats: one abbreviated pictorial presentation and a second detailed presentation that provides a short summary of the intentions and objectives of each Step.

The more detailed Checklist for an Essential Package of SRH lists and describes specific actions for each step, organized according to each of the WHO building blocks. Additionally, the first step, to "Prepare", includes some key actions on policy and advocacy, and each Step includes a description of key actions recommended to be taken with communities, without which the systems strengthening actions are unlikely to be successful. Each action item is recommended because of evidence derived from the literature review; the relevant evidence for each action is referenced and a summary provided in the matrix in the third section of this document.

For the third step in the Checklist, "Define and operationalize the essential SRH package", specific action guidance is provided for two types of essential SRH package, drawn from actual programmatic experiences. While these serve as concrete examples for two particular types of SRH package, most of the recommended actions would be appropriate for other essential packages of SRH services that a country may be interested in developing.

The evidence supporting these two tools is cumulated in the two appendices of this package. Appendix A is a matrix compiling all the relevant information collected in the international literature review, serving as the evidence-base for these tools. Appendix B is the comprehensive bibliography of this international literature review. 


\section{Steps for Planning and Implementing an Essential Package of SRH Services}

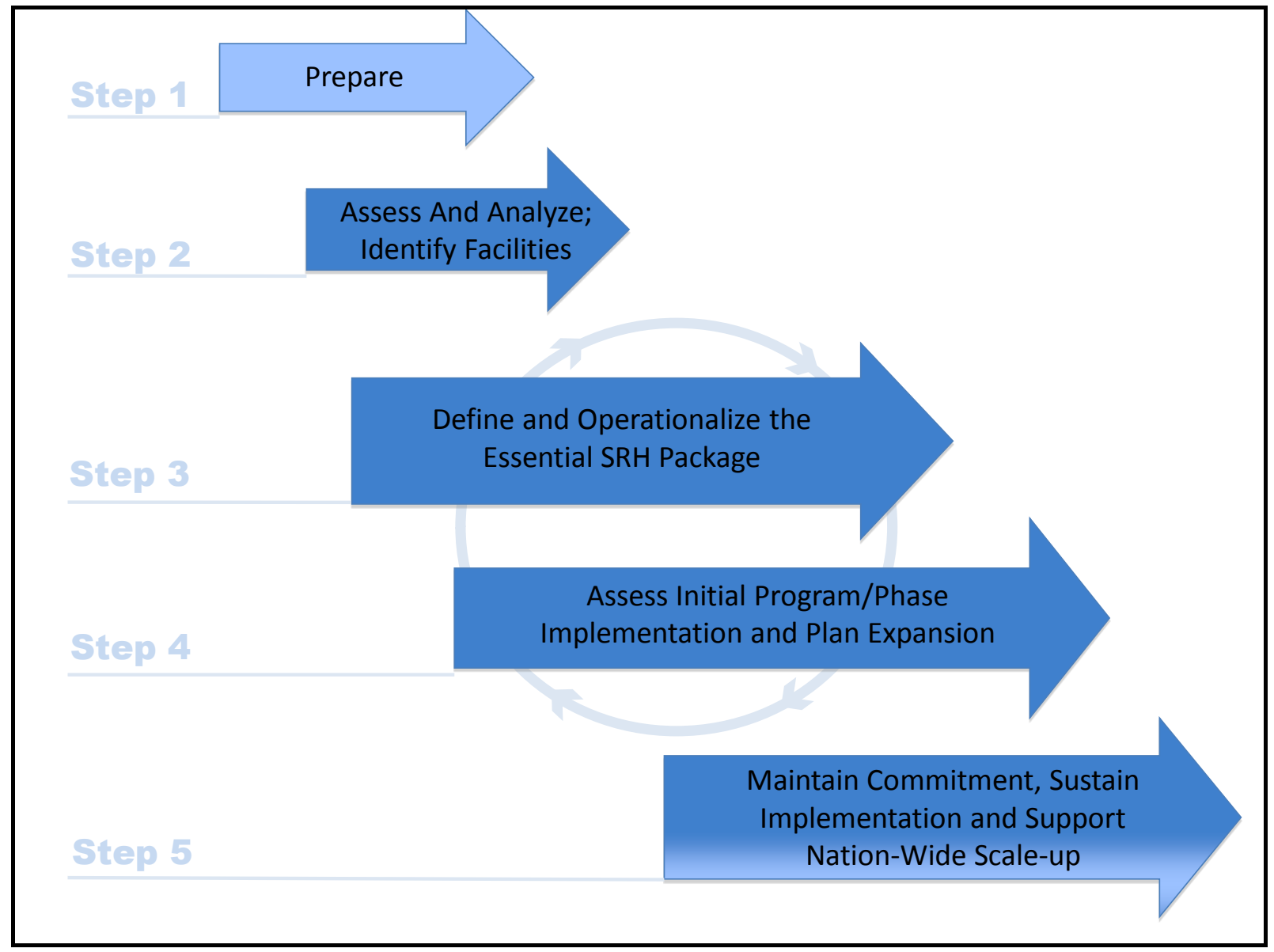




\section{Steps for Planning and Implementing an Essential Package of SRH Services}

\section{STEP 1: PREPARE}

Before building a new, or strengthening an existing, package of essential SRH services, key relationships must be created and strengthened and a strategic plan prepared. Partnerships should be sought with political and programmatic decision-makers, NGOs and organizations representing civil society, as well as community leaders and representatives. Preparation of a strategic plan will outline the steps of planning and implementation, identify partners and their responsibilities, and lay out a timeline and budget.

\section{STEP 2: ASSESS AND ANALYZE;}

\section{IDENTIFY FACILITIES FOR INITIAL PROGRAM/PHASE IMPLEMENTATION}

During the Assess and Analyze Step, systematic data collection and documentation is essential in order to determine the components of, and setting for, implementing an essential package of SRH services. Examples of information to be generated include: prevalence and incidence of the relevant SRH conditions; existing and successful programs delivering component services; existing policies and strategies, national plans and budgets, applicable laws and treaties; and the capability of partners at all levels. Defining potential gaps and required resources will also inform the reach and potential impact of the envisioned package.

\section{STEP 3: DEFINE AND OPERATIONALIZE THE ESSENTIAL SRH PACKAGE}

Definition and operationalization of the essential SRH package entails intensive discussions, negotiations between health system units responsible for each service, and decision-making before a prototype package can be developed and introduced. With information from assessment and analysis step, program managers and partners can together decide which services the package will comprise, and the resources needed to design, implement and evaluate the package.

\section{STEP 4: ASSESS INITIAL PROGRAM/PHASE IMPLEMENTATION AND PLAN}

\section{EXPANSION}

To learn from initial experiences with implementing the essential package of SRH services, nationwide expansion needs to follow a stepwise approach. Starting in facilities that have the capacity to strengthen systems and to monitor all inputs and outputs closely, lessons learned from initial implementation should guide program expansion if the essential package is clearly documented to be effective, safe, appropriately configured and an efficient use of resources. Communication, education and advocacy at the community level, as well as at all levels of the primary health care system, are critical for successful and sustainable expansion.

\section{STEP 5: MAINTAIN COMMITMENT, SUSTAIN IMPLEMENTATION AND SUPPORT}

\section{NATIONWIDE SCALE-UP}

Sustainability thrives with commitment and advocacy at policy level, as well as efficient health systems, quality service delivery, community-support, promotion of rights, and communication strategies, such as social marketing. Scale-up of an essential package of SRH services should include further strengthening of partnerships and commitment from stake holders and decision makers, including community-leaders, members and private and non-profit organizations. 


\section{The Checklist for Planning and Implementing an Essential Package of SRH Services}

\section{Policy/Advocacy}

- Gain policy-level support for delivery SRH services through an essential package by highlighting the benefits and challenges of this approach compared with existing service delivery approaches for SRH services. Utilization of existing or the development of new policy briefs may assist in this process.

- Use economic, health and human rights arguments to support a comprehensive SRH package. Ensure inclusion of such concepts as poverty, gender, age, ethnicity and sexual orientation in program planning and implementation.

- Create a leadership mechanism such as a committee or a working group for advocacy purposes that engages strong and influential partners within the $\mathrm{MOH}$ and other relevant ministries and sectors. These include government sectors of women's affairs, finance, education, planning and development; key NGOs; UN and other international development partners; medical professional associations; and civil society representatives. These partners should be recruited as potential 'champions' to advocate within their own organizations.

\section{Health Systems}

- Prepare a strategic plan that identifies key phases and milestones (preferably with a timeline and budget) for transforming existing SRH service delivery systems to a system capable of delivering a comprehensive SRH package.

- Undertake participatory appraisals among representatives of health system (finance, information, medicine and technologies) and managers at all levels to determine acceptability of this strategic plan and obtain feedback.

- Obtain commitment and encourage financial support from the various departmental / divisional directors who will collaborate directly in planning, budgeting and implementing comprehensive SRH services, including the Ministry of Finance.

- Ensure strong communication and collaboration between all relevant sectors of the health care services to be integrated within a comprehensive package, such as HIV sector, FP, Maternal and Child Health, STI/RTI prevention and treatment.

\section{Community}

- Undertake participatory appraisals with community leaders and members, and particularly intended beneficiaries and their representatives (e.g. health advocates, women's, youth and faith-based organizations' groups' representatives, etc), to determine acceptability of the plan, obtain input to fine-tune it, identify community roles in planning and monitoring delivery of services, and gain support for a comprehensive package. 


\section{Health Systems}

\section{Service Delivery:}

- Assess the quality of care and time utilization for the SRH services to be integrated. Evaluate existing delivery procedures and protocols for each component service to identify opportunities for offering a more integrated package of SRH services, including a functioning referral system between different levels, taking into consideration country-context, national policies, and international guidelines.

\section{Human Resources:}

- Assess human capacity of management systems, including competencies, skills and attitudes of providers, supervision and organization of staff, and identify capacity-strengthening needs where required.

\section{Health Information:}

- Review the existing health management information system (HMIS) to determine whether it produces complete, accurate and timely information for monitoring and evaluation of activities and results.

\section{Medicines and Technologies:}

- Undertake a review of existing commodity procurement and supply logistics for each component service, ensure that all necessary equipment and supplies can be routinely made available at the relevant service delivery points, and clearly define logistic management responsibilities if different units are involved.

\section{Health Financing:}

- Calculate existing costs of delivery of SRH services using standard costing procedures that can be used to determine marginal costs and cost savings of providing services through a comprehensive package compared to existing service delivery approaches.

- Consider approaches to reduce inequities in health care by removing financial barriers and provide free FP and pregnancy/maternal health services (including eliminating ancillary costs) to all; especially the poor, the young, the marginalized and people in conflict areas.

\section{Leadership and Governance:}

- Assess existing facility, district and higher level management systems for delivering individual and combined SRH services. Identify capacity-strengthening needs, including reorganization and linkages between different units and departments.

- Systematically document the current policies and approaches to delivering the SRH services that are to be integrated within a comprehensive package. Review current and recent national policies and programs, global commitments and policy/programming guidance from UNFPA, WHO, international donors and technical assistance agencies, and identify gaps and barriers to be addressed to enable a comprehensive package to be delivered.

- Identify in consultation with $\mathrm{MOH}$ and other partners whether to start in a selected number of facilities or districts and scale up in a step-wise approach or plan for national implementation.

- If a step-wise approach is agreed upon, select initial facilities or districts where: SRH indicators are poor; transforming health systems to offer a comprehensive SRH package would be unproblematic and appropriate; there is commitment and support from local stakeholders; and the introductory process could be easily and systematically monitored and documented. 


\section{Community}

- Assess care-seeking behaviors for SRH services. Identify social barriers and facilitators to utilization of existing SRH services (e.g. gender dynamics, religious beliefs, cultural norms), especially within the most vulnerable and marginalized populations. Decide whether a comprehensive package would increase access, reduce unmet need and improve SRH behaviors and practices. This may require re-analyzing existing datasets or commissioning new studies.

- Map and describe the potential for an expanded role for community-based resources in advocating, q.1-q.2 offering, and monitoring a comprehensive package of SRH information and services, such as community health workers, health committees, women's or youth groups, or faith-based organizations, among others. 


\section{Health Systems: $\underline{\text { STI/RTI integration into PHC }}$}

\section{Service Delivery:}

- Drawing from the information generated during step 2 and from available international guidelines, design a model for reconfiguring SRH service delivery so that a comprehensive package can be delivered that will be feasible and acceptable in the country setting. The following standards should be followed:

i) Reducing barriers to services;

ii) Raising awareness in the community;

iii) Promoting services;

iv) Reaching out to people who do not typically use reproductive health services.

- Reach population groups that are often at higher risk of STIs and who do not usually attend PHC services (especially SRH services); especially men, young people and sex workers.

- Promote community-level and clinic-based (group or individual counseling) prevention and treatment education to ensure that STIs/RTIs awareness is raised including the role of untreated STIs/RTIs in infertility, pregnancy complications and HIV infection.

- As required, create new (or modify existing) service protocols, job aides and information, education and communication (IEC) materials that are culturally-acceptable and published in language(s) and literacy levels appropriate for providers and the clientele.

- Where syndromic management is the recommended protocol, assess the feasibility and affordability of including laboratory diagnosis in service delivery strategy. Consider aspects of human resources, infrastructure, management and supervision, costs, supplies alongside potential benefits in terms of diagnosis-specificity.

- Strengthen the referral system with facilities that are able to provide diagnostic tests when needed.

\section{Human Resources:}

- Engage with national experts to adapt existing validated training approaches specifically for enabling SRH providers to counsel, screen, diagnose and treat STI/RTIs.

- Disseminate new / revised service delivery guidelines, training and supervision materials and introduction strategies to all health service managers and ensure understanding of and commitment to the integrated, comprehensive package approach to services delivery (e.g. integrating STI/RTI prevention and treatment services into family planning services, into antenatal, postpartum and delivery services, into newborn care services).

d.9

e.1-e.4

e. 9

f.10-f.14

g.1-g.7

g.14 g. 15

i. 26-i.29

p.13-15

q. 4 q.5

q.7q.9

q. 12 q. 14

q. 16

- Encourage task shifting to increase range of services that can be offered.

\section{Health Information:}

- Review and revise HMIS to collect and record data on RTI/STI services; include mechanism to monitor referral system, if relevant.

- Establish a systematic mechanism for documenting and monitoring the introduction and implementation of the comprehensive package(s) so that the experience can be learned from.

\section{Medicines and Technologies:}

- Increase facilities' capacity to undertake basic STI laboratory tests appropriate to their level and their capacity to provide all medications needed for syndromic or etiologic management.

\section{Health Financing:}

- Document costs of integration, estimate the annual implementation costs so that this information can inform nationwide expansion and potential scale-up. 


\section{Health Systems: $\underline{\text { STI/RTI integration into PHC }}$}

\section{Leadership and Governance}

- Confirm and maintain national level agreement with $\mathrm{MOH}$ and other relevant stakeholders to introduce the package of reconfigured services within existing service delivery policies and procedures.

- Seek commitment from MoH and other relevant stakeholders to revise policies, if necessary, during and after the comprehensive package's introduction.

- Create communication channels and regular opportunities for program management and policy makers to discuss the implementation, address challenges, barriers and bottlenecks and recommend improvements to implementation as they emerge through the documentation mechanism

\section{Health Systems: FP integration into MNH}

\section{Service Delivery:}

- Drawing from the information generated during step 2 and from available international guidelines for the relevant package of integrated services, design a model for reconfiguring SRH service delivery so that a comprehensive package of FP/MNH can be delivered that will be feasible and acceptable in the country setting. Integrated FP/MNH programmes should:

i) Offer a wide selection of methods

ii) Reflect high standards of medical practice

iii) Be sensitive to cultural conditions

iv) Provide sufficient information about proper use or possible side effects

v) Address women's other reproductive health needs

- Service provision policy should include systematic offering of contraceptive services in the first year after an obstetric event regardless of the reason for the visit, and especially to women taking infants for services.

- Develop innovative strategies to encourage men/husbands/partners to participate in family planning and other reproductive health services, to support wife/partner and also to seek services for themselves.

- Consider strengthening outreach community-based models in forms appropriate for/already in use in the country for ANC, PNC, immunization and FP.

- Create new (or modify existing) information, education and communication (IEC) materials that are culturally-appropriate and published in correct language(s) and literacy level.

- Develop efficient and realistic referral system that is feasible, considering aspects including transportation, costs, roads and infrastructure.

\section{Human Resources:}

- Promote changes in attitudes, management practices, system and organizational strategies to help a new practice take root (e.g. introduction of new FP methods/ integrating two services together).

- Disseminate new / revised service delivery guidelines, training and supervision materials and introduction strategies to all health service managers and ensure understanding of and commitment to the integrated, comprehensive package approach to services delivery (e.g. integrating family planning into antenatal, postnatal, newborn and intrapartum care services). 


\section{Health Systems: FP integration into MNH}

- Engage with national experts to adapt existing validated training approaches specifically for enabling SRH providers to counsel and provide FP services.

- Encourage and enable task shifting to increase range of contraceptives and services that can be offered through reviewing and revising policies and job descriptions.

\section{Health Information:}

- Review and revise HMIS to collect and record data on FP services; include mechanism to monitor referral system, if relevant.

- Establish a systematic mechanism for documenting and monitoring the introduction and implementation of the comprehensive package(s) so that the experience can be learned from.

\section{Medicines and Technologies:}

- Confirm that all FP commodities are available through current procurement and logistic systems. Identify alternatives or back-ups for those not available.

\section{Health Financing:}

- Document costs of integration, estimate the annual implementation costs so that this information can inform nationwide expansion and potential scale-up.

- Collect data for a cost-effectiveness analysis to compare services delivery through a comprehensive package with delivery through existing vertical systems.

- Explore new financing mechanisms such as demand-side financing, output based aid, franchising, and other public-private partnerships.

\section{Leadership and Governance:}

- Confirm and maintain national level agreement with $\mathrm{MOH}$ and other relevant stakeholders to introduce the package of reconfigured services within existing service delivery policies and procedures.

- Seek commitment from $\mathrm{MoH}$ and other relevant stakeholders to revise policies, if necessary, after the comprehensive package is introduced/while it is being introduced.

- Create communication channels and regular opportunities for program management and policy makers to discuss the implementation, address challenges, barriers and bottlenecks and recommend improvements to implementation as they emerge through the documentation mechanism

\section{Community}

- Work with the community to define appropriate community-based and health posts/dispensary services according to their needs, the capacity of potential workforce and infrastructure, and the relationship with higher-tiered facilities and services, including referral system.

- Define sensitization and mobilization activities for community members. Consider group discussions to address stigma, gender relations and communications.

- Consider higher-risk populations, including men and youth, in definition and implementation of strategy, such as gender- or age-specific service provision, communications and outreach activities targeted at these populations. 


\section{Health Systems}

\section{Service Delivery:}

- Record equipment, supplies and human resources requirements to efficiently provide laboratory services. If laboratories are feasible financially and infrastructurally, develop a scale-up strategy for health facilities, including needs and costs of supplies, required training for laboratory technicians, cold-chain and logistic strategies, as well as protocols and guidelines for use of and procedures within laboratory facility.

- Evaluate population-level impacts of comprehensive package, including gender, women's empowerment, men's involvement and other social dynamics. Review results and adjust future planning accordingly.

\section{Human Resources:}

- Develop a team of trainers (or update existing team of trainers) so that providers can be trained while scaling up integrated services. Train providers and other staff in the new / revised procedures, with follow-up and retraining after 3 months. Include service delivery guidelines and standards of practice, communications skills, counseling, case management, drug prescribing processes, and use of job aides and tools.

Explain all revised responsibilities for staff and supervisors. If job descriptions need revision, emphasize communication and counseling skills for service providers, and management and accountability for supervisors.

\section{Health Information:}

- Use updated HMIS to monitor service utilization and system performance at district level and enable comparisons between districts. Identify reasons for high and low performing districts and take appropriate action.

\section{Medicines and Technologies:}

- Ensure medicines/commodities listed in the service delivery guidelines and algorithms are consistently available in expansion districts by reviewing (and if necessary revising) the commodity logistics forecasting systems, including forms to facilitate calculations and requests.

\section{Health Financing:}

- Provide technical assistance to implementing districts so that they can incorporate the funding needed for rolling-out an integrated model into their annual district health plans.

\section{Leadership and Governance:}

- Ensure that integration of services is in the national plan and has a budget line attached to it and responsible bodies and units for activities are identified in the plan.

- If necessary, ensure that all pharmaceutical and health products/technologies needed for delivering the comprehensive package are registered and included in the national List of Essential Medicines.

- Make sure that the commodities and equipment necessary are in the national procurement plan and have a budget line dedicated to them.

Ensure that the monitoring plan of the national health plan includes scaling up of integrated services and indicators as well as baseline measures.

- Assess progress of implementation in initial districts and facilities, in terms of feasibility, appropriateness, and effectiveness. Build capacity of district / facility management teams to implement the new package.

- Develop a quality assurance plan to monitor implementation of new services package that emphasizes supervision, accountability and management in implementation of the comprehensive SRH services. 


\section{STEP 4: ASSESS INITIAL PROGRAM/PHASE IMPLEMENTATION AND PLAN EXPANSION}

\section{Community}

- Engage with community stakeholders in expansion districts to plan, mobilize resources, monitor and evaluate community-based services and activities. Raise awareness of services in higher-tiered facilities.

- Strengthen linkages between community-based and facility-based services throughout expansion area to further reach and impact of services.

- Increase demand for services delivered through a comprehensive package through district-wide behavior change communication (BCC) activities. 


\section{Health Systems}

\section{Service Delivery:}

- Establish routine review of guidelines and ensure regular updates.

- Ensure mentorship or on job training continues to provide specific skills updates where required.

Human Resources:

- Develop a five-year HR recruitment and deployment plan.

- Decentralize human resources deployment.

- Expand cadres of workers with basic clinical and community health competencies.

\section{Health Information:}

- Ensure HMIS continues to monitor utilization of services, client dynamics and satisfaction, provider dynamics and quality of services provided.

\section{Medicines and Technologies:}

- Review and update national procurement plan and distribution system to ensure functioning system for service providers to request medicines and technologies according to their needs.

\section{Health Financing:}

- Evaluate final costs of program and calculate potential costs of scaling up as well as identifying the sources of financial support and potential for sustainability.

\section{Leadership and Governance}

- Incorporate funding for comprehensive package within national annual operational plans and budgets, with agreement of Ministry of Finance.

- Maintain feedback loop between implementation level and national policy-making level to inform decisions and design of strategies, and to avoid creation of unrealistic or inappropriate policies.

- Determine scale-up period needed to achieve coverage and other targets in line with MDGs 4, 5 and 6 by 2015. Review regularly against shorter term benchmarks.

- Ensure routine follow-up and supervision to determine whether policies are being implemented at clinic level, including encouragement from senior officials.

- Ensure full ownership of all financial responsibilities and build leadership capacity for government and/or other program managers prior to withdrawal of external technical assistance and funding.

- Monitor program implementation, barriers and improvements and ensure target-oriented actions through hosting technical working group meetings regularly with relevant program managers and other decision makers.

\section{Community}

- Maintain collaboration with community members and leaders to ensure community and individual needs are addressed and equity in access to and use of services is improved, especially for vulnerable and marginalized groups.

Engage community members and leaders throughout expansion (through activities such as participatory evaluation, feedback and participation in meetings and decision-making) with intentions for complete community/local ownership. 


\section{INTEGRATING STI/RTI SERVICES INTO FP SERVICES}

- $\quad$ Discuss STI/RTI prevention and concerns with all family planning clients at each visit.

- $\quad$ Promote dual protection, through condoms alone or as a dual method, at every opportunity.

- Identify women who may need special attention through a formal risk assessment, yet remember that a negative risk assessment does not mean that a woman is not at risk.

- $\quad$ Assess risk for STI/RTI syndromes by asking questions and/or doing speculum and bimanual examination.

- $\quad$ Manage symptomatic women by following national syndromic management guidelines and without laboratory tests.

- $\quad$ Also screen for STI/RTI using laboratory tests whenever warranted and as determined by national guidelines

- $\quad$ Ask about symptoms in the partner. Women with symptomatic partners should be treated, and treatment for the partner should be arranged through carefully designed strategies for partner notification.

\section{INTEGRATING STI/RTI SERVICES INTO PREGNANCY, CHILDBIRTH AND POSTPARTUM SERVICES}

- Encourage women to attend antenatal clinic early in pregnancy to allow timely detection and prevention of STIs/RTIs.

- $\quad$ Screen women for syphilis at the first antenatal visit, preferably on-site and during the antenatal consultation. Make results and treatment available before the woman leaves the clinic if possible.

- $\quad$ Offer screening for other STIs/RTIs, including cervical infections, if possible

- Ask women at each antenatal visit about STI symptoms in themselves and their partner. Offer screening and/or treatment of partners for at least symptomatic STIs, syphilis and HIV, through carefully designed partner notification.

- $\quad$ Counsel and test for HIV on-site; refer women who test positive to PMTCT services.

- $\quad$ Promote STI prevention during pregnancy for protecting both mother and child, and safeguarding future fertility.

- Identify infections that may not have been detected during antenatal period through STI/RTI screening during labor and delivery. Manage STIs/RTIs in the newborn.

- $\quad$ Give prophylaxis for ophthalmia neonatorum to all newborn babies.

- $\quad$ Review syphilis test results and evaluate the newborn for signs of congenital syphilis. 


\section{Pre-pregnancy}

- Advise women to wait at least 2 years after childbirth before stopping contraception to become pregnant again

- Advise women to eat a balanced diet at least 3 months before stopping contraception to get pregnant and to continue through pregnancy

\section{During pregnancy:}

- Use ANC as an entry point for a broader package of health services that take into account women's overall health needs

- Ask the woman about plans for having more children. If she (and her partner) want more children, advise them to wait at least 2-3 years between pregnancies for the health of the mother and children.

- Counsel on FP and birth spacing after delivery during the first ANC visit. Give information to take home and provide more detailed discussion in the third trimester of pregnancy.

- Encourage pregnant women to develop a birth plan and a postnatal/postpartum/FP plan. Explain that after birth, if a woman has sex and is not exclusively breastfeeding, she can become pregnant as soon as four weeks after delivery and so it is important to start thinking early about what FP method they will use.

- Inform her that the timing of starting a method after delivery varies depending intention to breastfeed or not.

- Advise women who chose a long term or permanent method of contraception to plan for delivery in hospital or a health centre where providers are trained to carry out the procedure.

- Ensure counseling and informed consent for immediate post-delivery sterilization and IUD insertion prior to labor and delivery.

\section{Labor, delivery and postpartum period:}

- Check if client has made any requests for long acting and permanent methods of FP to be commenced following admission during early labor

- Perform sterilization immediately postpartum if the woman chooses female sterilization if there is no sign of infection (ideally within 7 days, or delay for 6 weeks).

- Insert intrauterine device (IUD) immediately postpartum if the woman chooses this method and there is no sign of infection (following expulsion of placenta and up to 48 hours, or delay 4 weeks).

- Advise a woman that for maximum protection she should not wait until return of her menses to start contraceptive method but should start as soon as guidance allows (depending on breast feeding status)

- Method options for breastfeeding women can be used immediately postpartum and include:

lactational amenorrhoea method (LAM), condoms, female sterilization (within 7 days or delay 6 weeks), intrauterine device (IUD) (by 48 hours or delay 4 weeks)

Method options for non-breastfeeding women can be used immediately postpartum and include: condoms, progestogen-only oral contraceptives, progestogen-only injectables, implant, female sterilization (within 7 days or delay 6 weeks), intrauterine device (IUD) (within 48 hours or delay 4 weeks)

- Method options for breastfeeding women to be delayed:

6 weeks delay: progestogen-only oral contraceptives, progestogen-only injectables, implants,

6 months delay: combined oral contraceptives, combined injectables, fertility awareness methods

- Method options for non-breastfeeding women to be delayed

3 weeks delay: combined oral contraceptives, combined injectables, diaphragm, fertility awareness methods

Advise on correct and consistent use of condoms for dual protection from sexually transmitted infections or HIV and pregnancy

- Use every opportunity to discuss FP including when women bring their infants for immunization or when they are sick 


\section{Appendices}

Appendix A: Evidence-Base for Planning and Implementing an Essential Package of Sexual and Reproductive Health Services: An International Literature Review

Appendix B: Bibliography 


\section{Appendix A: Evidence-Base for Planning and Implementing an Essential Package of Sexual and Reproductive Health Services: An International Literature Review}

The Evidence-Base for Planning and Implementing an Essential Package of SRH Services provides a tabular representation of an international literature review that includes over 300 research articles outlining and providing recommendations on the planning and implementation of an essential package of SRH services.

These findings serve as the evidence-base supporting the Checklist for an Essential SRH Package and also frame the chronological steps and descriptions outlined in the Steps for Planning and Implementing an Essential Package of SRH Services.

The evidence-based is organized into the six Building Blocks of Health Systems (WHO, 2007): Leadership and Government, Service Delivery, Human Resources, Health Information, Medicines and Technologies, and Health Finance. A Community section follows the Health Systems section, providing evidence to support action points for community-level activities necessary for the successful implementation of an essential package of SRH services. At the conclusion of the Evidence-Base Matrix, Key Resources for planning and implementing an essential package are listed with website addresses and a brief summary provided for each.

Each piece of evidence is given a letter and a number which is referenced in the Checklist's righthand column, entitled "Links to Evidence". Here, references that support the action item are listed to allow the user to find and review the actual evidence-base supporting each action point. The full citation of each evidence-base is available in the Bibliography (Appendix B).

\section{Methods for International Literature Review:}

For this review, database searches were conducted on PubMed (MEDLINE), Popline, and the Internet. Two separate searches were conducted: 1) STI/RTI integration into Primary Health; and 2) Family Planning services integrated into Maternal Newborn Health care services. The review included published articles, abstracts, full papers and presentations from international conferences, program reports, unpublished papers, PowerPoint presentations, and personal communications with selected experts with extensive experience managing integration of services (family planning and STI/RTI programs specifically). The websites of the following key international organizations sponsoring or reporting FP/MNH and STI/RTI related research and programs in developing countries were also searched manually: the Population Council, UNFPA and World Health Organization.

The STI/RTI into PHC literature review included the following keywords: SEXUALLY TRANSMITTED INFECTIONS OR REPRODUCTIVE TRACT INFECTIONS, AND PRIMARY HEALTH CARE, ANTENATAL CARE SERVICES. A total of 196 documents were reviewed.

The FP into MNH literature review included the following keywords: FAMILY PLANNING AND MATERNAL HEALTH, OR PRENATAL CARE, OR POSTPARTUM OR POSTNATAL OR SAFE MOTHERHOOD OR FAMILY PLANNING, OR ANTENTATAL CARE, OR MATERNAL HEALTH SERVICES. A total of 145 documents were reviewed. 
Appendix A: Evidence-Base for Planning and Implementing an Essential Package of

Sexual and Reproductive Health Services: An International Literature Review

\begin{tabular}{|l|l}
\hline Topic & Evidence-base and Citations \\
\hline
\end{tabular}

HEALTH SYSTEMS: LEADERSHIP AND GOVERNANCE, INCLUDING POLICY/ADVOCACY

(1) There is power in partnerships. Strengthen partnerships and country-wide ownership with involvement of government officials, parliamentarians, other sectors (education, finance, gender) international organizations, civil society including

a) Partnerships women's groups, providers and private sector and donors in identifying new areas of cooperation and program of action for comprehensive SRH (Budiharsana 2002; Liambila et al 2009; Lush 2002; Ravindran and de Pinho 2005; UK All Parliamentary Group 2009; WHO 2008b).

(2) An integrated SRH health system is one where all players have a common vision and work in partnership towards agreed health goals (Berer 2003).

(3) Clarity is needed on how different national SRH bodies and partners relate to each other and to regional and district health authorities (Mayhew 2003).

(4) A champion among providers is need. This would be someone who is familiar with gender and cultural-relevance of integration (Budiharsana 2009).

(5) The Takamol project in Egypt reactivated an integration steering committee (a platform for decision making regarding integration which assists the MOH in developing public-private partnerships for social responsibility initiatives) (USAID 2005).

(6) The National STI Technical Working Group in Kenya was mandated with a research agenda, and the coordination of STI/RTI research activities and dissemination of findings. Teamwork was important in the development of the training materials and enhanced ownership in Kenya (NASCOP 2009).

\section{Partnerships with government}

(7) MOH leadership is necessary for consensus, supportive service and guidelines (Bhuiya and Rob 1998; Liambila et al 2009).

(8) Local governments often favor curative over preventative services (Schierhout and Fonn 1999).

(9) A Bangladesh study partnered with National Institute of Population Research and Training and district level officers in their development and implementation (Hossain et al 2004; Rob et al 2002).

(10) India program had collaboration with SIFPSA (USAID-funded government run program), and district health authorities which was key to integration (Population Council 1998).

(11) Kenya program had good working relationship between district health management teams, National AIDS/STI Program and other public collaborations (NASCOP 2009).

(12) Partnership should be made at all phases: in development of training materials/BCC materials, sensitization, and the implementation process (Hossain et al 2004; Rob et al 2002).

\section{Partnerships with NGOs, INGOs, women and community groups}

(13) The capacity of civil society partners at local, regional and national levels is important. Failure to invest in capacity assessment and development of partners threatens sustainability of program (Brenny et al 2002).

(14) Central polices are required to support linkages/integration. They should incorporate community input and allow for local level modification and ownership (UK All Parliamentary Group 2009; WHO 2008b).

(15) Partnerships with women's-based and rights-based NGOs were made in Indonesia to ensure that training was gender-sensitive. Program in Indonesia gave grants directly to NGO, who hosted training and required physicians and universities to collaborate with the local NGOs to receive the funding (Budiharsana 2009). 
(16) In Africa, few NGOs and women's groups are represented. Religious organizations have power at community level but are not always interested in FP and STI programs (Liambila et al 2009).

Partnerships with medical universities/pre-service training institutions, medical/nursing associations

(17) An advisory board of national experts, clinicians, and leaders created the protocols and instructed the training courses for medical providers in Indonesia (Budiharsana 2002).

(18) Partnership with National ObGyn Association and FIGO affiliates was the best way to capture all physicians, set up the training for all providers and create a "mandated" feel to integration (Budiharsana 2009).

(1) Economic, health and human rights arguments must be used to persuade Ministers in national and international forums (Lush 2002; Mayhew et al 2000; UK All Parliamentary Group 2009).

b) Policy (2) Build political commitment within countries to ensure that crucial medical supplies and commodities are appropriately funded Framework within national health plans and budgets (UK All Parliamentary Group 2009).

(3) Effective legislative framework and policies must be informed by evidence and be translated into action with sufficient funding and strong political will to guide integration (Birungi and Onyango-Ouma 2006; Lush 2002; UK All Parliamentary Group 2009).

(4) Vertically-funded technically specialized offices (MNH, FP, HIV and STIs) at national level restrict the potential to plan effectively in an integrated manner (Lush 2002).

(5) Development of formal mechanisms for priority setting and advocacy could help secure benefits for SRH in the context of full range of health needs and realistic policies (Lush 2002; Mayhew 2003).

(6) Operational tools, protocols and trainings that function separately result in weak coordination of services at programmatic level (The Partnership for Maternal, Newborn and Child Health 2006).

(7) The criteria used for prioritizing services for essential package include: (1) levels of fertility and mortality; (2) disease burden; (3) cost effectiveness of available health interventions; and, (4) the capacity of the health system to deliver health services (Pachauri 1995).

(8) Policy development should be informed by mapping from both provider and client perspective. It should consider cultural context, women's status and empowerment, barriers to care seeking and health-seeking behaviors (WHO 2008b).

(9) Develop policies that integrate universal access to FP, skilled care before, during and after childbirth, and emergency obstetric care in the event of complications (UNFPA 2008).

(10) Current policies emphasize clinical-level and give lesser priority to preventative information/eduation/communication, counseling, partner tracing, as well as services for men and sexually active unmarried women. Policies should change to highlight role of these in epidemic (Mayhew et al 2000).

(11) FP strategic plans should offer clients easy access to a wide range of affordable contraceptive methods through multiple service delivery channels in a good quality, reliable fashion (Richey and Salem 2008).

(12) Should portray FP as a poverty and gender issue (UNFPA 2008). In Bangladesh, the Matlab project provides evidence that FP and MCH programs also help lift families out of poverty (UNFPA 2009).

(13) Transparency and participation of stakeholders is a priority in setting SRH/MNH health policies at national and local levels (Alvarez-Castillo et al 2005).

(14) Need a legislative framework to guide integration (Lush 2002).

(15) Without routine follow-up and supervision, determining whether policies are being implemented at the clinic level is difficult (Mayhew et al 2000).

\section{Provider and training policies}

(16) Strong opposition is seen within medical hierarchy from doctors towards services being provided by nurses (even when nurses are trained and nurse-provided services are within national guidelines) (Lush 2002; Mayhew et al 2000).

(17) Need for national provider curriculum that emphasizes training for all staff (medical and administrative). Also need to ensure the legality of all medical-providers prescribing STI drugs (Mayhew et al 2000). Law in Kenya requires physician's approval for prescription; nurses can conduct clinical exam but must refer for prescription (Maggwa et al 1997b). 
Assessment of current prevalence, rates and programs

\section{Evidence-base and Citations}

(18) Unless STI management is including in national training curricula, nurses and providers who are trained to diagnose and manage STIs will be difficult to retain (Mayhew et al 2000).

(19) Best practices of FP integration should be widely publicized among providers and among community (Yeboah 2005).

(1) Include an assessment of burden, epidemiology, population dynamics, and country context (management, existing services and delivery structure, their use, resources, staff capacity/skills staff motivation, attitudes, responsibilities and operating procedures), clinical capacity to provide integration, referrals and health-seeking behaviors. Want to know where people access care and why, what services should be offered, and the ways stigma/discrimination discourage utilization of services (Church and Mayhew 2009; IPPF 2000; Lush 2002; UNFPA 2004a; WHO 2008a; WHO 2008b).

(2) Questions to ask include in assessment include: What type of service integration, if any, is needed? To what extent should services be integrated? What steps are needed to establish and sustain high-quality integrated services? What information is needed to measure program success and inform service delivery improvement, replication, and scale-up? (WHO 2009).

(3) Existing health-service structure and capacity determines the true effectiveness and cost-effectiveness of integrating care (Church and Mayhew 2009).

(4) Need country-specific approaches with qualitative data to explain service statistics and feedback from existing programs. For example, the cause of syphilis varies in low and middle income countries (Mayhew et al 2000; Schmid 2004).

(5) Identifying the timing of the initiation of contraceptive use after a birth has key implications for designing family planning programs to meet women's needs for contraception (Alva and Dougherty 1999).

(6) Costs, performance, quality, milestones and timeframes are monitored and controlled for variances within the projected plan (Teffo-Menziwa 2010).

\section{HEALTH SYSTEMS: SERVICE DELIVERY}

(1) The lack of a specific government framework and budget to support integration hinders progress. Parallel systems for planning, funding, management, reporting, commodity distribution and supervision causes confusion (Birungi and OnyangoOuma 2006).

d) Service provision
(2) There is little evidence to date whether integration confers improvements in service quality and client satisfaction (Church and Mayhew 2008; Dehne et al 2000).

(3) Creating service configurations for integrated services can place a strain on the underlying logistics, training, supervisory, and management systems, especially if the services are provided through different programs (as is the case with SRH and HIV/AIDS services). It may also overstretch service providers with limited skills and support (Rivero-Fuentes et al 2008a).

(4) Health systems should be strengthened at all levels through equitable distribution of health workers and access to basic and emergency obstetric services. Should upgrade facilities and ensure that they are accessible, affordable, appropriate and acceptable with trained staff, essential drugs, contraceptive commodities, supplies and equipment. It is a long and arduous process, but there are no shortcuts (Richey and Salam 2008; UK All Parliamentary Group 2009).

(5) 'Packages of care' are more realistic to provide than individual interventions (Kerber et al 2006).

(6) An integrated service can bring together different health providers and create a closer relationship between health centers and district hospitals. I may also form joint efforts across sectors (Schierhout and Fonn 1999).

(7) Linkages that add information (prevention messages and screening) are easier to implement than linkages that require extensive clinical judgment for referral or clinical treatment (WHO 2008a).

(8) Community issues and health system issues should be addressed together (de Graft-Johnson 2005).

(9) Key concerns for women seeking health care include respect, trust, privacy and confidentiality. These values are often compromised in busy facilities, particularly among certain age groups and social groups (WHO 2009).

(10) The continuum of care for health of mothers, newborns and children provides a framework whereby single evidence-based interventions can be combined and delivered in packages according to local needs and capacity (Kerber et al 2007). 
(11) There are eight service delivery packages available, depending on common service-delivery strategies and common target populations throughout the lifecycle of the mothers, newborns, babies and children (Kerber et al 2007).

(12) Opportunities to integrate FP into MNH include: ANC; post-delivery; postpartum period; and, immunizations (Mwangi et al 2008; Vernon et al 2008; Warren et al 2008a; Warren et al 2008b).

(13) Gaining administrative, technical and political support is the most vital stage for initiating the process of integration. (Rob 2010).

(1) More than 50\% providers said that they were uncomfortable discussing sexual behavior with clients (Church and Mayhew 2009; Maggwa et al 1999b).

e) Counseling (2) Providers at all services (ANC, post-delivery, child health, and FP) missed opportunities to counsel clients on the full range of contraceptive methods (Hatzel et al 2008).

(3) Integration improved providers' counseling skills and performance in FP services (Dehne et al 2000).

(4) Care is more complete and client satisfaction improves when gender and sexuality issues are addressed (Askew and Maggwa 2002; IPPF/WHR 2000).

(5) Integrated counseling is rare. Most counseling for STIs is done at the end of a visit, after FP or MCH counseling (Askew and Maggwa 2002; Dehne and Snow 1999).

(6) The Balanced Counseling Strategy Plus (BCS+) provides a framework for integrated counseling for FP and STI /HIV risk assessment (Mullick et al 2008).

(7) Group counseling on sexuality and practices showed to be effective in Brazil. The BENFAM project facilitated communication with partners (Badiani and Becker 1994).

(8) In Bangladesh, systematic screening and behavior change communication materials were integrated into care, yet providers were still reluctant to use materials during counseling sessions (Talukder et al 2009).

(9) Program staff need to understand the link between SRH and STI services to reduce the potential sensitivities and stigma associated with providing new services (IPPF/WHR 2000).

(10) The introduction of new comprehensive post-natal care package improved the performance of providers in counseling about maternal and newborn complications, infant feeding and FP (Warren et al 2008a).

(1) IEC materials and preventative activities are not emphasized as much as they should be, particularly among large population groups who may be responsive to IEC and community prevention (such as men and unmarried women who do not use MCH/FP services) (Church and Mayhew 2009).

f) Job aides/ tools and IEC materials

(2) Balanced Counseling Strategy Plus improves quality of care (Liambila et al 2008).

(3) Following introduction of service protocol for improving ANC and PNC, the range of services received by both mother and baby increased, particularly FP (Jacobs et al 2002).

(4) Increasing awareness and knowledge is not enough to achieve objectives of FP programs (Lush 2002, Ndwiga 2010)

(5) Educated women could act as useful agents of change towards the elimination of practices harmful to the health of mothers and their children (Iliyasu et al 2006).

(6) Checklist and guidelines already exist. One review found that 11 of 32 programs developed thei own materials and 13 were working on own IEC materials (Dehne and Snow 1999).

(7) Checklist for providing integrated consultation improves the provision of integrated counseling messages (Askew and Maggwa 2002; Dehne and Snow 1999; Maggwa and Askew 1997).

(8) Recommend a checklist for lab supplies to keep lab functioning (Population Council 1998).

(9) Systematic Screening improved providers' competence in client screening and questions about FP. It also increased the provision of services, improved client-provider interactions including greeting, respect and privacy. Yet inquisition of previous signs/symptoms/treatment was still low (Talduker et al 2009) .

(10) Prevention measures (IEC materials and community-level mobilization) are cost-effective in the long-run (RamaRao et al 1996). 
(11) IEC materials and preventative activities are not emphasized as much as they should be, particularly among large population groups who may be responsive to IEC and community prevention, such as men and unmarried women who do not use MCH/FP services (Church and Mayhew 2009).

(12) IEC materials need to be based on evidence and research. Qualitative research should take place before implementation takes place and researchers should not assume clients know (Dallabetta 1996; FHI n.d.).

(13) Many IEC materials are produced centrally and therefore messages are in wrong language and/or message is inappropriate (Mayhew et al 2000). IEC materials are physically lacking in all surveyed facilities. Materials that were available were in English (Maggwa and Askew 1997; Mayhew et al 2000).

(14) IPPF recommends gearing IEC materials and advertisements towards men, to normalize condom use and also familiarize them with symptoms (IPPF 2000).

(1) All services should be offered at one site (Liambila 2009).

(2) Reach and quality of the pre-existing service largely dictates quality of integrated services (Dehne et al 2000).

g) Facility $\quad$ (3) Rural health posts may benefit from having different services on different days (Lush 2002).

Infrastructure (4) Consider providing different levels of care at different facilities. Depending on the extent of treatment/diagnosis needed, the client can be referred to higher "tiered" services (Rob et al 2002).

(5) Takamol project in Egypt has encouraged private investment in rehabilitating health facilities to provide integrated services (USAID 2005).

(6) To provide integrated services, a facility requires: essential equipment for pelvic exams; ANC; PNC; drugs; counseling skills; IEC materials; trained staff; efficient clinic-management systems; and functioning referrals (Mayhew et al 2000).

(7) Postpartum centers that are attached to the women's hospital attract a high client-load because of their location and the availability of lab services (Population Council 1998).

(8) Water supplies and cleanliness of facilities is still an issue even with facility provides high quality care and has laboratories (Hossain et al 2004; Rob et al 2002).

\section{STI/RTI service integration}

(9) Add STI services onto preexisting/high quality FP/MCH services or women-oriented care. If services added onto facility where staff already familiar with pelvic exams and syphilis screening, there is less needed change and training (Dehne et al 2000; Lush 2002; O'Reilly et al 1999; Population Council 1998; UNFPA 2004b).

(10) Recommendation to decrease any stigma that would be associated with STI clinics by associating them with already popular and high-client facilities (Khan et al 1997; UNFPA 2004b).

(11) To provide integrated services, a facility requires: essential equipment for pelvic exams; ANC; PNC; drugs; counseling skills; IEC materials; trained staff; efficient clinic-management systems; and functioning referrals (Mayhew et al 2000).

(12) Recommendation to provide STI care in same facility but at different hours or through a different door to increase utilization (to address privacy and stigma issues) (UNFPA 2004b).

(13) Recommendation to provide services at higher level of facility (post-partum centers or community health centers in India) because training will be cheaper, lady doctors are available, standard of care can be more easily maintained (RamaRao et al 1996; UNFPA 2004b).

Laboratory infrastructure

(14) Lab facilities must be up to standards and equipped (including reagents) for successful integration and correct diagnosis of STIs but they are not always available (Budiharsana 2002; FHI n.d.; Lush 2002; Population Council 1998).

(15) Where lab equipment is available, costs to add integrated services would be marginal (Maggwa 1999a; Thompson et al 1999).

(16) Lab equipment and facilities are available and stocked, yet doctors prefer to use clinical methods of diagnosis (Budiharsana 20009; Dehne et al 2000; Hossain et al 2004; Rob et al 2002).

(17) Decentralized syphilis testing in clinics leads to more women with syphilis detected and treated than centralized testing. Decentralization lends to cost-effectiveness and is preferred by nurses (Schmid 2004). 
(18) On-site syphilis testing procedures should be simple. New testing techniques are shown to be cost-effective (Schmid 2004).

(19) Resources needed in laboratory include: slides, cover slips, syringes, needles, reagents, wet mounts, Gram Staining (WHO 2005).

\section{Antenatal care}

h) Family planning integrationspecific service provision

(1) ANC is a potential entry point for a broader package of health services that takes into account women's overall health needs (WHO 2009).

(2) Although women (in China, South Africa and Scotland) found FP information useful in ANC, it had little effect on contraceptive use and subsequent pregnancy (Smith et al 2002).

(3) In South Africa, when women attending ANC were provided with appropriate information they made decisions about when to initiate contraception (Hani et al 2003).

(4) If women are properly counseled about postpartum FP during ANC they are more likely to adopt a method before discharged from the health facility following childbirth. There needs to be adequate referral mechanisms between primary care facilities (that provide ANC) and secondary care facilities (that provide delivery services). There needs to be counter-referral for follow up of women who will receive PPFP before discharge from health facility (Abdel-Tawab 2010).

\section{Labor and delivery/postpartum care}

(5) Post-placental IUCD insertion has been successfully introduced in Kenya and Zambia (Borda et al 2009).

(6) Integrating FP in postpartum period suggests improvements in client satisfaction (Mwangi et al 2008; Abdel-Tawab et al 2008; Warren et al 2008b).

(7) Comprehensive postpartum care increases uptake of family planning (Vernon et al 2008).

(8) Providing FP in the immediate postpartum period can be more cost-effective than providing them after the six-week postdelivery period and can also contribute to higher contraceptive prevalence rates (Vernon et al 2008).

(9) Postnatal package of care includes: examination of mother and baby; advice on danger signs for mother and baby; immunization for infant; vitamin A for mother; counseling and provision of FP; screening for cervical cancer; risk assessment for STI/HIV; and, links to other services where necessary (including HIV services for mother and baby) (Mwangi et al 2008; Warren et al 2008a; Warren et al 2008b).

(10) In Chile, women valued being treated with respect, receiving education and support, being offered time-saving services and wider FP choices in one visit (Alvarado 1999).

(11) In Honduras intervention, the proportion of women receiving FP information either post-abortion or postpartum doubled and those receiving an FP method tripled (Medina et al 2001).

(12) In Vietnam, age, sufficient knowledge on contraceptives, and husband/partner's opinion significantly affected the contraception decision for postpartum women (Duong 2005).

(13) Lack of postpartum training for health providers, shortage of nurses (to conduct home visits), women's lack of knowledge about postpartum contraception, misconceptions (women wait for menses return before seeking FP services) and taboos (meeting a woman who menstruates interferes with breastfeeding) were among the major obstacles to providing integrated PPC in Egypt (Abdel-Tawab 2010; CATALYST Consortium n.d,) .

(14) Few women knew when fertility returned following an abortion or delivery (Mwangi et al 2008; Vartapetova et al 2006; Warren et al 2008a).

(15) Women's preference on contraception initiation is influenced by their knowledge of post-delivery return of fertility, their parity, and the method desired (Population Council 2008).

(16) Women who are given an appointment for the postpartum visit, or who were provided with written or verbal information on maternal health, were more likely to return for that PNC visit (Kabakian-Khasholian and Campbell 2005)

Integration shown to improve providers' counseling skills and performance in FP services (Dehne et al 2000).

Immunization

(18) In Togo, the introduction of a referral messages for women bringing infants for immunization was accompanied by an $18 \%$ 
increase in awareness of FP services and increase in average monthly number of new FP clients by 54\% (Huntington and Aplogan 1994).

(19) Two key characteristics of success were compatibility between interventions and presence of a strong immunization service prior to integration (Wallace et al 2009).

\section{National guidelines and standards of care}

(20) Establish need for guidelines and regular updates (Kenya adapted WHO Medical Eligibility Criteria for contraception and updated FP guidelines in 2003 and 2009) (Liambila et al 2009).

(21) Birth spacing messages have been integrated into service delivery guidelines for antenatal and postpartum care, in training curricula for health care providers, and in supervision checklists (FRONITERS 2008).

(22) In addition to national guidelines and strategies, international guidelines can be adapted by considering local-specific priorities (Rob 2010).

(1) STI prevention can take the form of counseling, informing clients STI transmission and prevention, increasing women's ability to negotiate condom use, and promoting reduction in number sexual partners, (Haberland et al 2002).

i) STI/RTI integrationspecific service provision

(2) Dual protection is the most feasible and immediate step towards integration of STI and FP (O'Reilly et al 1999).

(3) Not all services should be integrated because of the following three arguments: 1) FP clients may not be at disproportionately high risk for STI; 2) Delivery and management requirements not always operationally compatible; and 3) Lack of simple effective technologies for diagnosis and treating asymptomatic women (Fleischman-Foreit et al 2002).

\section{Syndromic Management (SM)}

(4) Syndromic management is essential (particularly where resources are limited) (Askew and Maggwa 2002; Dehne and Snow 1999; FHI n.d.; IPPF/WHR 2000; Population Council 1998; Rob 2009; UNFPA 2004b).

(5) SM is effective for men with urethral discharge and men/women with ulcers but ineffective for diagnosing vaginal discharge, cervical infections and leads to over treatment (Askew and Maggwa 2002; Church and Mayhew 2009; Haberland et al 2002; Maggwa 1999b).

(6) Sensitivity and specificity of SM increased with risk assessment (Dehne and Snow 1999; Maggwa and Askew 1997). Risk assessment is part of model for providing HIV/STI services in Kenya (Liambila et al 2009; Waburu et al 1997). Must be used to identify infections associated with cervicitis (Mullick et al 2005).

(7) Adding risk assessment to service provision adds no time to client's visit. Including a pelvic exam adds 15 minutes to length of visit. Collecting lab specimens adds 17 minutes for women who had risk assessment and pelvic exam (Maggwa et al 1999b).

(8) Adding vaginal exam to SM somewhat improves performance, however many women with infections were still missed (Askew and Maggwa 2002).

(9) Switching from WHO algorithm to SM algorithm with microscopy did not improve the diagnosis of cervical infections, but did improve the diagnosis of vaginal infections in Vietnam (Haberland et al 2002).

(10) Adding lab services to risk assessment did not result in increased number of infected women correctly identified and treated, but did remove wasteful treatment (Maggwa and Askew 1997).

(11) Over-diagnosis with SM is high. Only 7\% of tests provided with treatment were positive when lab-tested (UNFPA 2004b).

National guidelines and standards of practice: Syndromic Management

(12) In Kenya, many facilities did not have copies of national guidelines. There, government is interested in widely disseminating the guidelines and unifying STI management (Liambila et al 2009).

(13) Despite guidelines and laboratory facilities being available, doctors depend on clinical assessment and reported symptoms to make diagnosis (Budiharsana 2009; Dehne and Snow 1999; UNFPA 2004b).

(14) A potential reason for physicians to ignore guidelines (particularly those of syndromic management with decision-making algorithms) is that they circumvent the providers' authority (IPPF, 2000).

(15) Readiness and quality is shown to increase in clinics when additional resources are used to integrate services (Askew and Maggwa 2002). Clients are more satisfied with integrated services when there are lab support services, when there was a free 
(16) Quality-assurance teams visit all facilities for quality assurance and provider-client observations (Rob et al 2002; Hossain et al 2004; Teffo-Menziwa 2010).

(17) SM guidelines are not always fully followed, particularly the risk assessment component (Askew and Maggwa 2002; Budiharsana 2002; Dehne et al 2000; Lafort et al 2003; Maggwa et al 1999a; Mayhew et al 2000).

(18) In India, NACO guidelines recommend syndromic approach with three different variations depending on the availability of laboratories, speculum, microscopes (Khan et al 1997).

(19) Aggregation of results suggests that risk factor algorithms, risk scoring for syndromic management are poor indicators for gonorrhea and Chlamydia in both low and high prevalence. They are not effective mechanisms to identify/manage these infections (Sloan et al 2003)

\section{other diagnosis strategies}

(20) In high prevalence settings, presumptive treatment may be of value (Maggwa and Askew 1997). Misdiagnosis and false treatment is high when there is a low prevalence of STI/RTI. At 5\% prevalence of 4 diseases, presumptive treatment of all women coming in may be cheaper than diagnosis and treatment (Dehne and Snow 1999).

(21) Providers rely on pelvic exams for clinical diagnosis rather than SM flowchart (Dehne et al 2000).

(22) Providing women with information and allowing them to self-assess their own risk and choose their own FP method is as effective as assessment algorithms used by providers (Askew and Maggwa, 2002).

(23) FP clients spontaneously reporting their symptoms is not effective way of identifying infection. Asking all FP clients and examining them for symptoms of STI was more effective than asking each client about signs and symptoms, but was still not optimal (Maggwa et al 1999a).

\section{Partner notification}

(24) Partner notification is essential to STI prevention and treatment (FHI n.d.; Haberland et al 2002; IPPF 2000; Mullick et al 2005), particularly with ANC syphilis programs (Schmid 2004).

(25) Population Council programs in 4 African countries showed that partner notification was extremely difficult and ineffective: women did not want anyone to know about treatment or communicate with partners Outreach workers were related to or friends of women-this caused discomfort (IPPF 2000). Partner notification is continually documented as a difficult component of STI care (Mullick et al 2005).

\section{Referrals and follow-ups}

(26) Time-consuming and risk alienating clients before they complete diagnosis or treatment (Askew and Maggwa 2002; Budiharsana 2009).

(27) Referral system should include a follow-up and tracking system to ensure service utilization (Liambila et al 2009).

(28) Follow-up visits only at $20 \%$ in Zimbabwe case study with syndromic management. This low rate causes difficulties when additional or alternative treatment is necessary (Maggwa et al 1999b).

(29) In a South African study where women were asked to return 14 days after syphilis testing in ANC setting, the mean number of days of return was 20, and 1 in 5 were not notified of follow-up (Mullick et al 2005).

\section{HEALTH SYSTEMS: HEALTH WORKFORCE}

(1) Organizational problems include the lack of coordination between personnel, appointments and transfers and the training program, problems with routine drug supplies, and problems with referral systems to other levels of care (Schierhout and Fonn 1999).

j) Human Capacity and Provider

(2) Often staff morale can be a bigger barrier than lack of financial resources (McIntyre and Klugman 2003).

(3) If integration program given to one particular staff in organizational structure, the rest of staff will not be involved. Must include all staff and high-level management commitment (Becker et al 1997; Lush 2002). 
Characteristics

(4)

the full package of maternal health care including FP (UNFPA 2008).

(5) Decentralize human resources deployment. Poor and rural districts have more flexibility to offer adequate working conditions and retain staff (Mayhew 2003; Warren et al 2008b).

(6) Expand cadres of workers with basic clinical and community health competencies such as enrolled nurses, clinical officers and community health workers (Hall 2007).

(7) Higher-trained providers were better at implementing protocols and following guidelines. As qualifications fell, abidance to guidelines also decreased (Budiharsana 2009).

(8) There are concerns that staff would be overloaded with work once care was integrated, yet these concerns are incorrect. Reviews demonstrate that STI prevention activities improve provider attitudes, counseling skills and performance without overburdening them (Askew and Maggwa 2002; Lafort et al 2003).

(9) Increase in work load without adequate compensation affects morale of providers (Mukaire 1997).

(10) Must determine how staff is spending their time before considering adding new staff or even expanding existing obligations of staff. Many have substantial free time and therefore would only require training to increase service delivery (Maggwa and Askew 1997; Maggwa 1999a). With this, cost-effectiveness would improve because greater productivity would be achieved upon integration (Church and Mayhew 2009).

(11) Volunteerism is not reliable for sustaining health activities (FHI n.d.)

(12) In India, women object to pelvic exams by men. Facilities with female doctors were only ones with successful integration. Postpartum clinics only ones with lady doctors (PC, 1998). In Bangladesh, male providers to see male patients (Hossain et al 2004; Rob et al 2002).

(1) Phased and gradual training is often best (IPPF 2000). Bangladesh introduced intervention in phased manner, with interactive orientation and demonstration: 1) orientation to RTI/STI, 2) hands-on trainings, 3) case management (Bhuiya and Rob 1998).

k) Training

(3) Training curricula can be developed from the national guidelines (Population Council 1998).

(4) African governments should commit $25 \%$ of national budget to health and conduct comprehensive training needs assessments (Hall 2007)

(5) Training for provision of FP for post-abortion and postpartum clients led to an increase in FP uptake (Medina et al 2001).

(6) Improve providers' capacity including comprehensive and appropriate training for health care providers to meet the requirements and expectations of different subpopulations (Bharat 2008).

(7) Training should not be too hard, as providers will not be able to absorb it all at one time. It should also not be too light, or it will be considered unimportant and there will be no discipline (Budiharsana 2009).

(8) Four-days of training was efficient in India for ObGyns who were already treating infections (Khan et al 1997; Population Council 1998).

(9) Curriculum in Indonesia included infection diagnosis, case management, counseling skills, and ethics (Budiharsana 2002)

(10) Clinical training conducted by local doctors of university and medical department (Hossain et al 2004; Khan 2009; Rob et al 2002).

(11) In Indonesia, integration training provided through medical universities was the best way to access all physicians (who work in both public and private service delivery). Public sector positions were more prominent and physicians wanted to show their dedication to this training for personal gain/reputation purposes (Budiharsana 2009).

\section{Refresher training}

(12) Refresher training for providers and lab technicians should be provided three months after initial training (Budiharsana 2002).

(13) One training is not adequate to change providers' knowledge and ability to correctly diagnose clients (Budiharsana 2002).

(14) Partner notification significantly improved with two stages of provider training and an emphasis on this service delivery strategy during training (Budiharsana 2002). 


\section{Evidence-base and Citations}

(15) Regular coaching of health providers in their work environment improves the quality of care, which leads to greater client flow and a healthier population (USAID 2005).

\section{Counseling and sensitivity training}

(16) Interpersonal and sexual counseling-skills training has positive impacts on the quality of FP counseling (including training on overcoming cultural barriers, meaningful discussion about sexuality and partner relationships, resistance to new tasks and attitudes towards counseling) (Becker et al 1997; Dehne et al 2000).

(17) In sexuality curriculum implemented (Becker et al 1997), all staff were trained on counseling skills, sensitization, and familiarization with sexuality, empathy, listening, and clients' needs. Medical staff was provided additional training on medical management of STIs (Hossain et al 2004; Rob et al 2002).

(18) In Indonesia, provider training demonstrated improvement in overcoming cultural concerns, STI stigma and partner referrals (Budiharsana 2002).

\section{Monitoring and follow-up of training}

(19) Mentorship or on-the-job training can provide specific skills updates where required (Ndwiga 2009).

(20) Training should include 6-8 week period where providers are observed and monitored to ensure correct implementation of lessons learned in training (Budiharsana 2009). Providers need direct and immediate supervision after training and throughout first year of application of training (Khan 2009).

(21) Supervision will not happen by doctors (they are not trained themselves and many times do not know the guidelines and expectations). In India, medical experts checked quality during follow-up of training. Should train doctors and hospital managers to allow them to monitor implementation of new procedures and provider guidelines (Khan 2009).

\section{Laboratory technicians' training}

(22) Laboratory technician training should include practical and theoretical content, techniques to identify infections, and general lab procedures (sterilization of glassware, maintenance of equipment, quality control, registration, record keeping) (Population Council 1998).

(23) In India, recommendation for 5 days lab tech training with NACO guidelines (national guidelines) as a guide. Also recommend follow-up and re-orientation after 3 months, and providers would require supervision during that follow-up period (Population Council 1998).

(24) Lab technicians voice excitement about new job obligations. They are eager to learn and capable to carry out tests when provided resources to do so (Khan et al 1997).

(1) Recommend to have "lines of authority" between managers and policy makers for functioning integration (Mayhew et al 2000).

(2) Providers' and managers' involvement in planning improves providers' satisfaction with, and motivation to, offer integrated services (Church and Mayhew 2009).

l) Management and

(3) Management and vertical programs lead to problems with bureaucracy, with reporting upwards, and fostering reluctance to make decisions without approval. There is a reluctance to pass criticisms up the chain (Mayhew et al 2000).

Supervision

(4) Takamol project in Egypt supports increased management capacity of MOHP clinics, district offices, and governorate offices through an enhanced governorate-level supervisory system and improved financial management systems (USAID 2005).

(5) Integrated district plans include the integration of service provision, district level supervision and activities to create a a stronger link between the community and the facility. This includes activating clinic boards (USAID 2005).

(6) Recommendation to have routine follow-up and supervision to determine whether policies are being implemented at clinic level. This should also include encouragement from senior officials (IPPF 2000; Mayhew et al 2000; Talukder et al 2009). In Bangladesh, teams were created on policy and supervision level to check intervention's implementation; they visited all facilities for quality assurance and conducted provider-client observations (Hossain et al, 2004; Rob et al 2002).

(7) Making changes in provider's behaviors and attitudes, management practices and systems, and organizational strategies help a new clinical practice to take root and facilitate introduction of a new FP method (MSH 2004).

(8) District Health Management Teams conducted monthly supervisory visits to service provision posts with on-the-job updates 
(9) Motivation for providers stemmed from quality supervision and feedback, utilization of data at facility and district levels, and receipt of feedback from headquarters (NASCOP 2009).

\section{HEALTH SYSTEMS: HEALTH INFORMATION}

\begin{tabular}{|c|c|c|}
\hline $\begin{array}{l}\text { m) Health } \\
\text { Information }\end{array}$ & $\begin{array}{l}(1) \\
(2) \\
(3) \\
(4) \\
(5) \\
(6) \\
(7)\end{array}$ & $\begin{array}{l}\text { Process indicators are required to measure actual implementation of integrated models. Recognition of the common issue that } \\
\text { logically unites relevant sectors (WHO 2008b). } \\
\text { M\&E and reporting forms are regularly unrevised or updated. Programs continue to follow old record systems of vertical } \\
\text { programs (Dehne and Snow 1999). } \\
\text { Registers were updated to capture programs' intervention (Warren et al 2008b; Warren and Liambila 2004). } \\
\text { At facility level, registers are all separate for vertical reporting. It is challenging to measure how many services a client might } \\
\text { receive in one day, as registers only measure services provided (Ndwiga 2009). } \\
\text { Need a feedback-loop from implementation level to national policy making level to inform decisions and designs of strategies. } \\
\text { This will also assist to avoid creating unrealistic or inappropriate policies (Mayhew et al 2000). } \\
\text { MDG Target 5b indicators: CPR; unmet need for FP; \% of total demand satisfied; adolescent birth rate; ANC coverage; \% of } \\
\text { demand satisfied for FP; and skilled attendance at birth rate (UN Statistics Division 2008). } \\
\text { Positive indicators used in review of successful integration services include: increase client satisfaction; improve service } \\
\text { uptake by expanding range of services provided; expand reach of services to nontraditional clients; reduce STI- and HIV- } \\
\text { related stigma through provision of services not related with HIV/STI care; improve quality of care (including clinical, } \\
\text { interpersonal and coordination of care); improve organizational effectiveness of service provision, including cost-effectiveness; } \\
\text { and, influence behavioral health and social outcomes (Church and Mayhew 2009). } \\
\text { Recommended indicators for monitoring integrated programs include: percentage clients correctly managed for STIs; STI } \\
\text { prevalence in defined target population; percentage target group within unmet need; percentage clients screened } \\
\text { appropriately for RTI before IUD insertion -percentage FP clients accept a condom; composite indicator of female condom to } \\
\text { use condom; reduction in number of sexual partners of FP clients; increased condom use; and, improved care-seeking behavior } \\
\text { leading to early STI detection and treatment (Dehne and Snow 1999). }\end{array}$ \\
\hline
\end{tabular}

\section{HEALTH SYSTEMS: MEDICINES AND TECHNOLOGIES}

n) Medicines and Technologies
(1) Donor support necessary for steady supply of drugs (Dehne and Snow 1999). For example, Kenya has support from donors and government to integrate STI and FP logistics. Commodities are supplied together (Liambila 2009).

(2) Review current situation of availability of medicines/supplies. In review of 15 countries, 4 had drugs financed by public funding without donor support. In 3 countries, no relevant drug supply was based on national guidelines, and patients were referred to private pharmacies for prescriptions (Dehne and Snow 1999).

(3) Procurement and provision of FP commodities are challenged by stock outs and poor commodity procurement plans. Lack of initiative from senior district officials resulted in delays in arrival of medicines and reagents and products (Population Council 1998).

(4) Bureaucratic polices and delays for clearing imported commodities (Khan et al 1997).

(5) Public systems very rarely have ability to support supplies and drug systems. Outside funding is required in most cases for adequate and steady support for supplies and medicines (Lush 2002).

(6) Procurement and provision of STI treatment kits said to the most difficult component of integration (Lafort et al 2003). Lack of initiative from senior district officials resulted in delays in arrival of medicines and reagents and products (Population Council 1998). 
(7) Recommendation that all STI drugs and diagnosis supplies added to list and national procurement list (UNFPA 2004b). In Kenya, effort to review and change SM charts so that they are consistent with available drugs in national stock (NASCOP 2009).

(8) Serological screening for syphilis requires complicated chain of events, including drawing and transporting blood to reporting results back to the clinic. The inability to maintain testing service that requires transportation of blood to a centralized lab is a major barrier. Only 29\% of ANC clinics in South Africa had a functioning testing system for syphilis, despite a national screening policy (Schmid 2004).

(9) Improve training of pharmacists or people that deliver medicines. They are a source of education and information for clients, and can disseminate correct information about drugs and commodities (Gonzalez Salguero 2010).

\section{HEALTH SYSTEMS: HEALTH FINANCING}

(1) Data about costs of integration remains sparse (Church and Mayhew 2009). More cost-benefit analysis is needed at country level to strengthen the financial argument for investing in women's SRH at individual, household, community and national level

o) Health

Financing and (UK All Parliamentary Group 2009).

Costs

(2) Costs are dependent on year, service utilization rate, disease prevalence, type of facility where services provided, size of facility, IEC materials and quality of care, capital costs associated with building separate facilities for counseling, changes in clients' travel costs, and cost-effectiveness of integrated service in terms of averted births (Dehne and Snow 1999; RamaRao et al 1996).

(3) Large initial capital investment is necessary (Lush 2002).

(4) Many times, funding for FP and STI programs remain outside of SWAps because donors are interested in prioritizing particular areas and want more influence over the money (Lush 2002).

(5) Activity-specific funds that require vertical accountability returns can be highly disruptive of routine management and over reliance on external funding (Mayhew et al 2000).

(6) For public funding to work in MNH, it should be accompanied by a clear performance framework, transparency, and strict measures to address systematic corruption in health systems (Martines et al 2005).

(7) Ensure strengthened SRH advocacy at district level to help secure extra funds. District activities often funded separately (Lush 2002). Poor districts may need national "top up" funds to ensure adequate and regular supplies/commodities (Mayhew 2003).

(8) The biggest challenge for MNH/FP is mobilizing adequate resources. Must be cost effective and timely "to do more with less" as funds are never sufficient. (Berer 2003).

\section{Cost savings}

(9) "Wider integration would lead to $31 \%$ less costs than separate services for STI/HIV and FP, with savings from reduction in staff costs, supplies, and overhead." (UNFPA 2004b). Integrated care costs can be much reduced compared to non-integrated, especially if STI care is managed by nurses and not doctors (O'Reilly et al 1999).

(10) If effectiveness is measured by number of STI cases averted, targeted interventions are still the most cost-effective (Dehne and Snow 1999). Focusing on high-risk populations is always more cost-effective than focusing on low-risk family planning clients (Fleischman-Foreit et al 2002).

(11) Although evidence is still scarce, it is expected that the costs to the health system of configuring two or more services (provided either jointly at the same time and by the same provider or through referral) will be less than providing services independently (Das et al 2007).

(12) Incremental costs for integrating services are still more affordable compared to costs per client at stand-alone services (Liambila et al 2009; Lush 2002).

(13) When considering costs, must also consider costs of spending time giving ineffective care rather than reallocating time for effective care (particularly when considering syndromic management in settings where ineffective) (Sloan et al 2000). 


\section{Country examples of actual costs and savings}

(14) Uttar Pradesh, India: US\$3,429- US $\$ 5,245$ for first year of integration. Breakdown entailed $17 \%$ training, 7-9\% on capital equipment, $46-54 \%$ on IEC materials, $9 \%$ on lab tests, $14-21 \%$ on treatment. Second year, costs of IEC went down and costs of tests and treatment went up. Plus, second year included quality checks. Overall costs per clients are halved in $2^{\text {nd }}$ year (RamaRao et al 1996).

(15) Estimated US\$2.7 million (including both fixed and recurrent costs) needed to expand Bangladesh intervention at national level in the first year. Subsequent years would need US\$1.8 million (Rob et al 2002).

(16) A strategy to screen all clients by asking about signs/symptoms and use lab tests for those suspected of having RTI was used in Zimbabwe. This doubles the additional cost per client (from US\$5.30 to US\$10.30) and would still miss more than one-third of infected clients. But this strategy would decrease the number of wrongful treatments and allow provider to know exactly which infection each client had. Yet, strategy not considered affordable (Maggwa et al 1999a).

(17) US $\$ 25.77 /$ client is the additional costs per client if laboratory services were included in provision of care for FP clients. Presumptive treatment would include additional cost of US $\$ 13.50$ per client visits but would be wasteful with limited drugs and could lead to drug resistance (Maggwa et al 1999b).

(18) In Mombasa, Kenya, costs of Mkomani Clinical Society clinics providing MCH and STI services (among FP clinics choosing the pill who requires STI services) was calculated to be US $\$ 12.40$ with separate services and US $\$ 8.60$ with integrated services (not including capital costs such as training and renovations) (Twahir et al 1996).

(19) National Guidelines in Kenya say that the incremental costs to provide services to RH/PHC client were US\$0.1 per visit. Overall increased cost of integrating STI/RTI management in RH component were FP US $\$ 2.3$, ANC US $\$ 2.4$, Maternity US $\$ 3.43$, PNC US $\$ 1.36$, OPD US $\$ 2.50$ per client. Costs per client per visit by level of facility were US $\$ 2.59$ for hospital, US $\$ 2.76$ for health center, US\$2.67 dispensary (Liambila et al 2009).

(20) Total cost of national scale-up of STI/RTI/RH integration in Kenya over a 3 year period is US\$46.34 million. Over a 5 year period, would cost US\$48.74 million (Liambila et al 2009).

(21) Treatment kits for gonorrhea are approximately US\$6 per kit, and for Chlamydia US\$15 per kit (UNFPA 2004b)

(22) Costs of drugs for conditions in US, 2001:

Genital ulcer (syphilis, chancroid) US\$2.12; Urethral discharge US\$2.20; and Vaginal discharge (gonorrhea, Chlamydia, thrichomoniasis, candiasis, vaginosis) US\$2.55 (UNFPA 2004b).

(23) Costs for screening and diagnosis of 4 STIs in women (syphilis, Chlamydia, chancroid, gonorrhea) estimated between US $\$ 0.17$ and US\$5.10, depending on clinical or laboratory supported: (US\$0.32 for chancroid and US\$1.20 for gonorrhea) (Dehne and Snow 1999).

(24) Sub-Saharan Africa, economic analyses of direct medical costs for indicate that syphilis screening is cost-effective even at low prevalence. Cost of averting case of congenital syphilis was US\$50-177. Immunochromographic strip test used in South Africa (where prevalence high as 6\%) is more cost-effective at US\$37 per case averted (compared to RPR test at US\$43 and laboratory at US\$111) (Schmid 2004).

(25) Syphilis diagnosis and treatment should be free for clients (Schmid 2004).

(26) Supplies and Equipment costs (conversion of 30Rs to the US\$): microscope 10,000Rs; centrifuge 3000Rs; sterilizer 1000Rs; hot air oven 3800-4500Rs; burner 200Rs (RamaRao et al 1996).

(27) Training costs in India program are as follows:

MDs training: 200Rs/day/trainee (5-7 days), plus a 50Rs allowance and 350Rs travel allowance.

Lab tech training: 200Rs/day/trainee (7-15 days), plus 35Rs allowance and 150 travel allowance.

Health workers training: 3 days at block level 50Rs/day/trainee, 15Rs allowance and 40Rs travel allowance (RamaRao et al 1996). 
1) Limited community-level components to integration (Dehne et al 2000; Koblinsky 2005).

p) Service provision, mobilization and referral
(2) Local health committees used to promote integration, yet they were not as successful. Recommendation that local health committees need specific tasks (Schierhout and Fonn 1999).

(3) Subcommittees of health facilities trained in community mobilization, basic financial management and administrative procedures enabled higher buy-in and participation in the design and management of integration activities (Mukaire et al 1997).

\section{Family planning community-level service provision/mobilization/referra}

(4) In Nigeria, only 3\% of postpartum women could correctly report the at-risk period for getting pregnant during postnatal period. This is a wide gap between knowledge and use of family planning (Adebanjo et al 2005).

(5) In Chile, integrated interventions are possible for poor communities and can provide significant advantages to women and children (Alvarado et al 1999).

6) The success of integrating FP into ANC is likely to be dependent on its suitability to the particular social and cultural context (Keogh et al 2009).

7) Breastfeeding women in Egypt with unplanned pregnancies were less likely to have used contraception than women who had weaned. Prolonged breastfeeding contributes to unmet contraceptive need (Tilley et al 2009).

(8) Community-based PPFP programs are few in number and depend on community workers to provide women and families with information about where and when to visit clinics. But, where community-based family planning in properly implemented, there is greater contraceptive choice, method mix and continuation rates (Koblinsky 2005). For example, community midwives in Kenya provide integrated FP/MNH services (Mwangi and Warren 2008).

(9) Community groups consisting of community members, male paramedics and field workers organized meetings with local and religious leaders, adult males and adolescents. Government fieldworkers and community people were involved in educational activities and raises awareness about SRH and family planning among men (Hossain et al 2004).

(10) Women are still holding on to postpartum cultural beliefs and practices in northern Nigeria. Common postpartum practices include sexual abstinence (100\%), physical confinement (88\%), hot ritual baths (86\%), nursing in heated rooms (84\%) and ingestion of gruel enriched with local salt (83\%) (Iliyasu et al 2006).

(11) In India, community health workers dispelled common myths and misinformation about family planning and other health behaviors and corrected information to counter misperceptions (Khan 2008b).

\section{STI/RTI community-level service provision/mobilization/referral}

(12) Women in India are not using services because of lack of awareness, acceptance of RTIs as natural occurrence, and the lack of treatment facilities (Khan et al 1997).

(13) An inventory of 73 outreach programs in Africa concluded that $65 \%$ outreach programs included outreach to community (targeting schools, condom CBD, social marketing). Condom distribution through male agents can effectively promote condom use by men (Askew and Maggwa 2002)

(14) Recommendation to explore training and treatment by non-medical workers to reach community level. Also recommend that STI-control activities should be integrated within the community strategy, including updating CHWs on STI/RTI signs and symptoms, basic management and referrals (Askew and Maggwa 2002; NASCOP 2009; Twahir et al 1996).

(15) STI counseling, risk assessment, referral for diagnosis and management, partner notification may be integrated at community level (O’Reilly et al 1999). STI education through community workers was not shown to increase education and knowledge among community members (Askew and Maggwa 2002).

(16) Community-based outreach system in Mombasa included extension workers who raised awareness about FP, employed CHWs by salary, and referred many clients for STI/FP services at integrated facilities (Twahir et al 1996). 
(17) Need for simple, accurate, low-cost field diagnostic tools to be used at peripheral sites (Haberland et al 2002).

(18) BCC and condom promotion and counseling have not shown much impact (O'Reilly et al 1999). BCC messages would be more productive if they were directed at men, because the experience with women is not very productive (O'Reilly et al 1999).

(19) Radio messages were broadcasted with promotional activities and messages for available services (Hossain et al 2004; Rob et al 2002).

(20) Encouraging community participation to find and implement locally-appropriate strategies of STI/RTI prevention and care, the program needs continuous facilitation. In this case, public-private partnership may work (Rob 2010).

(1) Most facilities where integration happens are not where high-risk populations seek care (Mayhew et al 2000).

(2) Need to take into consideration the social and cultural factors to reduce unmet need (Adebanjo et al 2005).

q) Targeting hard-to-reach populations

(3) Encourage governments to reduce inequities in health care by removing financial barriers and provide free FP and pregnancy/maternal health services (including eliminating ancillary costs) to all (especially the poor, the young, the marginalized, and people in conflict areas). A variety of mechanisms exist to do this, such as equity and voucher schemes (Druce et al 2006; UK All Parliamentary Group 2009).

(4) Vouchers for safe delivery and family planning target poor women that demonstrate an increase in uptake of skilled attendance and long term FP methods (Kundu 2008).

(5) There are difficulties in reaching men and youth and other high-risk by simply adding services onto existing public programs (Askew and Maggwa 2002; Fleischman-Foreit et al 2002).

Men

(6) Integration provides a better opportunity for male involvement (Mphuru et al 2006). Programs must include men if want to reduce risk to women (Askew and Maggwa 2002).

(7) Strategies to create awareness on male SRH issues should be given priority at clinical and community levels. Health providers should be trained on male SRH needs (Onyango et al 2009).

(8) Male involvement encourages women to make informed decisions for FP uptake (Khanakwa and Damba 2008).

(9) Successful programs in Latin America succeeded by providing services for men outside of normal SRH clinic setting, where men congregated (Dehne et al 2000; IPPF 2000).

(10) In Turkey, clinic-based programs saw positive effects in the area of postpartum family planning after including men (Turan et al 2001). Involving husbands in FP counseling sessions during ANC led to joint decisions being made and encouraged women's use of FP postpartum (Soliman 1999).

(11) Services for men and youth sometimes benefit from being linked to services for women (Dehne and Snow 1999; Rob et al 2002). Integrating men services into existing women's services may be more rational as couples' care is logistically difficult (O’Reilly et al 1999).

(12) In Bangladesh, men's services were integrated into HFWC (government primary health care center at lowest administrative level). Both women and men showed comfort with services. Distinctions between service provider and exam rooms maintained gender separation. $100 \%$ male and $91 \%$ females reported not being uncomfortable with presence of opposite sex in service facilities (Hossain et al 2004; Rob et al 2002; Rob 2009).

(13) Two preferred approaches to reaching men include making condoms freely available at clinics, and encouraging men to accompany partners to ANC and FP visits where they are educated, provided condoms, tested and treated (Askew and Maggwa 2002).

(14) Group discussions in BEMFAM (Brazil program) showed positive effects, particularly when men were included to increase communication and empowerment of women (IPPF 2000).

\section{Youth}

(15) Youth-friendly services with FP and condom distribution, life skills counseling, and BCC are all recommended in addition to STI prevention and management services (UNFPA 2004b).

(16) Because youth are at high risk for both SRH issues (unwanted pregnancy) and STIs, it is essential to offer two services in the 


\section{Evidence-base and Citations} same setting (IPPF 2000).

(17) Use mass/local media to inform the public about integrated services. This is particularly effective for young populations who listen to main stream media (Teffo-Menziwa 2010).

(18) Ecologically-displaced populations should be considered because of their vulnerability to RTI/STI while they live in an unhealthy and over-crowded situation (Rob 2010) 


\section{KEY RESOURCES FOR PLANNING AND IMPLEMENTING AN ESSENTIAL PACKAGE OF SRH SERVICES}

\section{Assessing Integration Methodology (AIM) Toolkit}

http://www.popcouncil.org/docs/AIM Complete.doc

This toolkit guides decision-makers on how to assess the feasibility of linking services, identify programmatic or structural barriers to integration, pilot-test approaches to integrating services, evaluate the effect of linked or integrated services, and assess and evaluate the costs of models to integrate services.

\section{Balanced Counseling Strategy Plus (BCS+) Toolkit}

http://www.popcouncil.org/publications/books/2008_BalancedCounselingStrategyPLUS.asp

The Balanced Counseling Strategy Plus (BCS+) is an interactive, client-friendly approach for improving counseling on family planning and prevention, detection, and treatment of sexually transmitted infections (STIs) including HIV.

\section{Family Planning: A Global Handbook for Providers}

www.fphandbook.org

The handbook provides practical guidance on family planning methods and related topics that reflects the best available scientific evidence. It is a quick-reference resource for all levels of health care workers and reflects guidance developed by the WHO.

\section{Pregnancy Childbirth Newborn and Postnatal Care: A Guide for Essential Practice}

http://whqlibdoc.who.int/publications/2006/924159084X eng.pdf

This guide provides evidence-based recommendations to guide health-care professionals in the management of women during pregnancy, childbirth and postpartum period, and post abortion, and newborns during their first weeks of life. It is a guide for clinical decisionmaking.

\section{Systematic Screening}

http://www.popcouncil.org/publications/books/2008_IntroducingSystematicScreening.asp

Systematic screening is a simple strategy tool where providers use a checklist or brief questionnaire to identify each client's needs and desires for health services and then provide all these services during the same visit, through an appointment at the same clinic or through referral to another facility.

WHO Guidelines for Essential Practice (GEP) and Tools for the Control, Prevention and Management of STIs and RTIs in Various Settings and Among Different Populations

http://www.who.int/reproductivehealth/topics/rtis/evidence/en/index.html

This guide is a reference manual and a resource to educate and remind health-care workers of the need to consider sexually transmitted infections (STIs) and reproductive tract infections (RTIs) in providing other sexual and reproductive health services. It could be used for provider education and training, as a source of up-to-date, evidence-based recommendations, and as a self-education tool for health-care providers on the prevention, treatment, and diagnosis of RTIs. Program managers can use it as a starting-point for improving policies, programs and training on the prevention and management of STI/RTI, adapting the information and recommendations as needed to local conditions. 


\section{KEY RESOURCES FOR PLANNING AND IMPLEMENTING AN ESSENTIAL PACKAGE OF SRH SERVICES}

WHO Guidelines for the Management of STIs

http://whqlibdoc.who.int/publications/2003/9241546263.pdf

These guidelines provide treatment recommendations for comprehensive management of patients with STIs in the broader context of control, prevention and care programs for STIs and HIV. It covers both the syndromic approach to the management of patients with STI symptoms, and the treatment of specific STIs.

WHO Medical Eligibility Criteria for Contraceptive Use - 4th Edition

http://whqlibdoc.who.int/publications/2009/9789241563888 eng.pdf

The document provides recommendations for appropriate medical eligibility criteria for contraceptive use. It provides guidance to national $\mathrm{FP} / \mathrm{RH}$ programs in the preparation of guidelines for service delivery of contraceptives.

WHO Recommended Interventions for Integrated Management of Pregnancy and Childbirth

http://www.who.int/making pregnancy safer/documents/who mps 0705/en/

This pamphlet presents five tables that indicate those key interventions to be delivered through health services, the family and the community.

WHO Training Modules for the Syndromic Management of Sexually Transmitted Infections

http://www.who.int/reproductivehealth/publications/rtis/9789241593407index/en/index.html

This training course is intended for in-service training of people responsible for STI management at any first-level health facility, such as a health centre, district hospital, mission hospital or STI clinic. 


\section{Appendix B: Bibliography}

Abdel-Tawab, Nahla, Hala Youssef, Sarah Loza, Amal Zaki, Salwa Farag. 2006. Helping Egyptian women achieve optimal birth spacing intervals, through maximizing opportunities in antenatal and postpartum care. FRONTIERS Research Update No 9. Cairo, Egypt: Population Council.

Abdel-Tawab, Nahla, Sarah Loza, Amil Zaki. 2008. Helping women achieve optimal birth spacing intervals: Testing two models of providing birth spacing messages to pregnant and postpartum women. FRONTIERS Final Report. Washington, DC: Population Council.

Abdel-Tawab, Nahla. 2010. Personal Communication. Associate, Population Council Egypt. January 4, 2010.

Abou-Zahr, Carla Lidia, Tessa M Wardlaw. 2003. Antenatal care in developing countries: Promises, achievements and missed opportunities: An analysis of trends, levels and differentials 19992001. Geneva: World Health Organization (WHO).

Adebanjo B Adeyemi, Kayode T Ijadunola, Ernest O Orji, O Kuti, Marie M Alabi. 2005. The unmet need for contraception among Nigerian women in first year postpartum. European Journal of Contraception and RH care, 10(4): 229-234.

The Alan Guttmacher Institute. 2004. "Adolescents in Burkina Faso: Sexual and Reproductive Health,” Research in Brief Series, No.3. New York and Washington, DC: The Guttmacher Institute.

Alva, S, Leanne Dougherty. 1999. When is a good time to begin? Dynamics of contraceptive use among women in the extended post partum period in Africa. Washington, DC: Macro International/AIM and John Snow Inc/AIM.

Alvarado, R, A Zepeda, S Rivero, N Rico, S López, S Díaz. 1999. Integrated maternal and infant health care in the postpartum period in a poor neighborhood in Santiago, Chile. Studies in Family Planning, 30(2): 133-141.

Alvarez Castillo F, Sundari Ravindran Helen de Pinho. 2005. "Sexual and reproductive health in priority setting in health sector reform" in Rights and Reforms: Health Sector Reforms and Sexual and Reproductive Health. Ravindran, S and de Pinho H (Eds.). Johannesburg, South Africa: Women's Health Project/University of Witwatersrand.

Arma-Klemesu, M, D Arhinful, P Nyarko, H Birungi, S Deganus, H Odio-Agyarko, G Brew. 2006. Acceptability and feasibility of introducing the WHO focused antenatal care package in Ghana. FRONTIERS Final Report. Washington, DC: Population Council.

Askew Ian, NB Maggwa, L Kangas. 1998. “Integrating STI and HIV/AIDS services into MCH/FP programs in East and Southern Africa," presented at the 1998 Annual Meeting of the Population Association of America, Chicago, Illinois, 2-8 April. 
Askew, I, NB Maggwa. 2002. Integration of STI prevention and management with family planning and antenatal care in sub-Saharan Africa: What more do we need to know? International Family Planning Perspectives, 28(2): 77-86.

Badiani, R, J Becker. 1994. Brazil: HIV/STI prevention and family planning. Washington, DC: Population Reference Bureau.

Barber, SL. 2007. Family planning advice and postpartum contraceptive use among low-income women in Mexico. International Family Planning Perspectives, 33(1): 6-12.

Becker, J, E Leitman, F Fathalla. 1997. Introducing sexuality within family planning: The experience of three HIV/STD prevention projects from Latin America and the Caribbean. New York: Population Council.

Berer, Marge. 2003. Integration of sexual and reproductive health services: A health sector priority. Reproductive Health Matters, 11(21): 6-15.

Bhuiya I, U Rob. 1998. Strengthening RTI/STD services in FP-MCH program: Lessons learned from a pilot project. Asia \& the Near East Operations Research and Technical Assistance Project. Dhaka, Bangladesh: Population Council.

Birungi, Harriet, W Onyango-Ouma. 2006. Acceptability and sustainability of the WHO antenatal care package in Kenya. FRONTIERS Final Report. Washington, DC: Population Council.

Bishop, Meghan, Beatrice Okyundi, Carol Shepherd, Rachel Sanders. 2009. "Policy and operational barriers to FP and HIV integration in Kenya. Futures Group International,” presentation at International Conference on Family Planning Research and Best Practices, Kampala, Uganda, 15-18 November.

Borda, Maria Raquel, Bill Winfrey, Catherine McCaig, Angela Nash-Mercado. 2009. "FP use among postpartum women in 15 countries," presented at International Conference on Family Planning Research and Best Practices, Kampala, Uganda, 15-18 November.

Brenny, PJ, J Rakotoarisoa, A Bossuyt, C Randrianarisoa, V Randriamanalina, HN Rajaofara. 2002. "Civil society capacity building to improve STI and HIV/AIDS service delivery at the local level in Madagascar," presented at International Conference on AIDS, Barcelona, Spain, 7-12 July.

Budiharsana, M. 2002. Integrating reproductive tract infection services into family planning settings in Indonesia. International Family Planning Perspectives, 28(2): 111-112.

-----. 2009. Personal Communication. Senior Associate and Country Director, Vietnam, Population Council. November 1, 2009.

CATALYST Consortium. n.d. Best practices in Egypt: Integrated community-based postpartum care. USAID/CATALYST/TAHSEEN Project. 
Ching-Bunge, PJ. 1995. The integration of AIDS/STD prevention information into family planning programs in developing countries and the use of mixed messages. Community-based FP Services Project. Eschborn, Germany: Deutsche Gesellschaft für Technische Zusammenarbeit (GTZ).

Church, Kathryn, Susannah H. Mayhew. 2009. Integration of STI and HIV prevention, care, and treatment into family planning services: A review of the literature. Studies in Family Planning, 40(3): 171-186.

Collumbien, M, M Gerressu, J Cleland. 2004. "Non-use and use of ineffective methods of contraception," in Comparative Quantification of Health Risks: Global and Regional Burden of Disease Attributable to Selected Major Risk Factors. Ezzati M, AD Lopez, A Rodgers, CJL Murray (Eds.). Geneva: WHO. pp. 1255-1320.

Conde-Agudelo, A, A Rosas-Bermudez, A Cecilia Kafury-Goeta. 2006. Birth spacing and risk of adverse perinatal outcomes: A meta-analysis. Journal of American Medical Association, 295(15): 18091823.

Dallabetta GA, M Laga, PR Lamptey (Eds.) 1996. Control of Sexually Transmitted Diseases: A handbook for the design and management of programs. Arlington, Virginia: AIDSCAP/Family Health International.

Das, Rumeli, Kaushik Biswas, Pradeep Panda, ME Khan, Rick Homan. 2007. Strengthening financial sustainability through integration of voluntary counseling and testing services with other reproductive health services (India). FRONTIERS Final Report. Washington, DC: Population Council.

Dehne, KL, R Snow. 1999. Integrating STI management into family planning services: What are the benefits? Geneva: World Health Organization (WHO)/Department of Reproductive Health Research (RHR).

Dehne, KL, R Snow, KR O’Reilly. 2000. Integration of prevention and care of sexually transmitted infections with family planning services: What is the evidence for public health benefits? Bulletin of World Health Organization, 78(5): 628-639.

Druce, N, C Dickinson, K Attawell, AC White, H Standing. 2006. Strengthening linkages for sexual and reproductive health, HIV and AIDS: Progress, barriers and opportunities for scaling up. London: DFID Health Resource Center.

Duong, DV, AH Lee, CW Binns. 2005. Contraception within six month postpartum in rural Vietnam: Implications for family planning and maternity services. European Journal of Contraception and Reproductive Health Care 10(2): 111-8.

English, Mike, Grace Irimu, Annah Wamae, Fred Were, Aggrey Wasunna, Greg Fegan, Norbert Pershu. 2008. Health systems research in a low income country: Easier said than done. Archives of Diseases in Childhood, 93(6):540-544. 
Family Health International (FHI). n.d. Final Report for the AIDSCAP Program in Ethiopia Executive Summary (1993-1996). Accessed at <http://www.FHI.org/en/HIVAIDS/pub/Archive/aidscapreports/finalreportAIDSCAPethiopia /index.htm>.

Farrell, BL. 2007. Family planning-integrated HIV services: A framework for integrating family planning and antiretroviral therapy services. New York: EngenderHealth/The ACQUIRE Project.

Fleischman-Foreit, KG, K Hardee, K Agarwal. 2002. When does it make sense to consider integrating STI and HIV services with family planning services? International Family Planning Perspectives, 28(2): 105-107.

Fort, A, M Kothari, N Abderrahim. 2006. Postnatal care: Levels and determinants in developing countries. Calverton, MD: Macro International Inc.

FRONTIERS. 2008. Clinical guidelines for integrating family planning into postpartum and postabortion care. Cairo: Population Council and Ministry of Health, Egypt; Washington, DC: USAID.

de Graft-Johnson, Joseph, Patricia Daly, Susan Otchere, Nancy Russell , Robin Bell. 2005. Household to hospital continuum of maternal and newborn care. Baltimore: JHPIEGO/The ACCESS program.

Gonzales Salguero, Fernando. 2010. Personal Communication. Country Director Bolivia, Population Council. January 5, 2010.

Haberland, N, B Ndugga Maggwa, C Elias, D Measham. 2002. Pitfalls and possibilities: Managing RTIs in family planning and general reproductive health services. New York: Population Council.

Hall, S. 2007. People first: African solutions to the health worker crisis. London: African Medical and Research Foundation (AMREF).

Hani, A, M Moss, D Cooper, C Morroni, M Hoffman. 2003. Informed choice-the timing of postpartum contraceptive initiation. South Africa Medical Journal 9(11): 862-4.

Hatzel T, J Moodley, E Sutherland. 2008. "Serving the post-partum contraceptive needs of PMTCT clients," presented at the International Aids Conference, Mexico City, 3-8 August.

Hindin, MJ. 2007. Contraception and safe abortion to prevent maternal morbidity. Lancet, 370(9595): 1294-1295.

Hossain,Sharif Mohammed Ismail, Ubaidur Rob, ME Khan, Ahmed Al-Sabir, Mohammed Ahsanul Alam. 2004. Integration of male and female reproductive health services in Bangladesh with an emphasis on increasing male participation and awareness. Population Review, 43(2): 88-100. 
House of Commons International Development Committee. 2008. Maternal Health. Fifth report of Session 2007-08, vol 1. London: The Stationery Office Limited.

Huntington, D, A Aplogan. 1994. The integration of family planning and childhood immunization services in Togo. Studies in Family Planning, 25(3): 176-183.

Iliyasu Z, M Kabir, HS Galadanci, IS Abubakar, HM Salihu, MH Aliyu. 2006. Postpartum beliefs and practices in Danbare village, Northern Nigeria. Journal of Obstetrics and Gynecology, 26(3): 211-5.

International Planned Parenthood Federation (IPPF). 2000. Self-assessment module on integrating STI/HIV/AIDS services into sexual and reproductive health programs. New York: IPPF/ Western Hemisphere Region (WHR).

-----. 2002. Have you integrated STI/HIV prevention into your sexual and reproductive health services? New York: IPPF/ Western Hemisphere Region (WHR).

International Planned Parenthood Federation (IPPF), UN Population Fun (UNFPA), Joint UN Program on HIV/AIDS (UNAIDS), The Global Network of People Living with HIV/AIDS (GNP+), International Community of Women Living with HIV/AIDS (ICW), Young Positives. 2008. Rapid Assessment Tool for sexual and reproductive health and HIV linkages: A generic guide. Mexico City: IPPF.

Ipas. 2009. Reducing unsafe abortion in Ethiopia: Monitoring progress with the Safe Abortion Care (SAC) model in Tigray. Chapel Hill, North Carolina: Ipas.

Jacobs, Erika, Carlos Brambila, Ricardo Vernon. 2002. Reproductive health care in the postnatal period in Guatemala. FRONTIERS Final Report. Washington, DC: Population Council.

Janowitz, B, L Johnson, A Thompson, C West, C Marangwanda, NB Maggwa. 2002. Excess capacity and the cost of adding services at family planning clinics in Zimbabwe. International Family Planning Perspectives, 28(2): 58-66.

Kabakian-Khasholian, T, O Campbell. 2005. A simple way to increase service use: Triggers of women's uptake of postpartum services. Bulletin Journal of Obstetrics and Gynecology, 112 (9): 13151321.

Keogh Sarah C, Mark Urassa, Yusufu Kumogola, Julius Mngara, Basia Zaba. 2009. Reproductive behavior and HIV status of antenatal clients in northern Tanzania: Opportunities for family planning and PMTCT integration. AIDS, 23(Suppl.1): S27-S35.

Kerber, Kate , J Joseph E de Graft-Johnson, Zulfi qar A Bhutta, Pius Okong, Ann Starrs, Joy E Lawn. 2007. Continuum of care for maternal, newborn, and child health: from slogan to service delivery. Lancet, 370: 1358-69. 
Khan, ME, Saumya RamaRao, RB Gupta, Bella Patel, Leila Caleb, Jayanti Tuladhar, Sanjeev Kumar, John Townsend. 1997. Integrating RTI services in primary health care system: Observations from an operations research in Uttar Pradesh, India. Asia \& Near East Operations Research and Technical Assistance Project. New Delhi: Population Council.

Khan, ME, Mary Sebastian, Rukma Innani. 2008a. Promoting optimal inter-pregnancy intervals in India through integrated public delivery systems. FRONTIERS Final Report. Washington, DC: Population Council.

Khan, ME, Mary Sebastian, Usha Sharma, Rukma Idnani, Kaushal Kumari, Bharati Maheshwari, Shahid Ashraf. 2008b. Promoting healthy timing and spacing of births in India through a communitybased approach. FRONTIERS Final Report. Washington, DC: Population Council.

Khan, ME. 2009. Personal Communication. Senior Associate, Population Council India. November 4, 2009.

Khanakwa S, D Damba. 2008. "Men: The frontiers of success in family planning and PMTCT interventions in HIV/AIDS prevention," presented at International Aids Conference, Mexico City, 3-8 August.

Koblinsky, Marjorie A. 2005. Community based postpartum care: An urgent unmet need. Catalyst Consortium.

Kundu, Francis. 2008. A new initiative towards universal access to reproductive health in Kenya. National Coordinating Agency for Population and Development (NCAPD). Accessed at <http://www.ncapd-ke.org/UserFiles/File/RH-OBA/Project/RHOBA/Article\%/20March/2008.pdf> on Deb 10,2009.

Lafort, Y, Y Sawadogo, T Delvaux, B Vuylsteke, M Laga. 2003. Should family planning clinics provide clinical services for sexually transmitted infections? A case study from Cote d'Ivoire. Tropical Medicine and International Health 8(6): 552-560.

Liambila, W. 2009. Personal Communication. Program Officer, Population Council. November 15, 2009.

Liambila, W, R Ayisi.,M Gathitu. J Mwangi, R Homan, et al.. 2008. Feasibility, acceptability, effect and cost of integrating counseling and testing for HIV within family planning services in Kenya. FRONTIERS Final Report. Washington, DC: Population Council.

Liambila, W, S Mullick, I Askew, N Broutet, I Mohammed, C Awour, B Kigen, D Sande et al. 2009. Introducing and pilot-testing the national guidelines on integrating the management of STIs/RTIs into reproductive health settings in Kenya. New York: Population Council.

Low N, N Broutet, Y Adu-Sarkodie, P Barton, M Hossain, S Hawkes. 2006. Global control of sexually transmitted infections. The Lancet, 368(9551):2001-2016. 
Lubben, M, SH Mayhew, C Collins, et al. 2002. Reproductive health and health systems change:

Establishing a framework for dialogue. Bulletin of World Health Organization 80(8): 667-673.

Lush, Louisiana. 2002. Service integration: An overview of policy developments. International Family Planning Perspectives, 28(2): 71-76.

Maggwa, BN, I Askew. 1997. Integrating STI/HIV management strategies into existing MCH/FP programs: Lessons learned from case studies in East and Southern Africa. Africa Operations Research Technical Assistance Project II. Nairobi: Population Council.

Maggwa, BN, I Askew, C Marangwanda, et al. 1999a. Demand for and cost-effectiveness of integrating RTI/HIV services with clinic-based family planning services in Zimbabwe. Nairobi: Population Council.

Maggwa, BN, Ian Askew, Caroline Marangwanda, Barbara Janowitz, Laura Johnson, Andy Thompson, Caroline West. 1999b. The costs of integrating reproductive health services: An example using syndromic management of STIs in family planning clinics in Zimbabwe. Africa Operations Research Technical Assistance Project II. Harare, Zimbabwe: Population Council, Zimbabwe National Family Planning Council, and Family Health International.

Maggwa, BN, Ian Askew , Elizabeth Mugwe, Bilhah Hagembe, Rick Homan. 2001. A case study of Nairobi City Council's decentralized syphilis screening program in antenatal clinics. Nairobi: Population Council.

Management Sciences for Health (MSH). 1998. "Integrating STD/HIV services into reproductive health settings," The Manager, vol. 7 no. 3. Boston: MSH.

Management Sciences for Health (MSH). 2004. "Leading Changes in Practices to Improve Health," The Manager, vol. 13 no. 3. Boston: MSH.

Mannan, MA, Jafar Ahmad Hakim, Syeda Tazneen Waris, Ashraf Ali, AKM Nurul Hakim, Abdul Hannan, Sameena Chowdhury, Saria Tasnim, Saiful Islam, AQM Rezaul Karim, Sharif Mohammad Ismail Hossain, Ubaidur Rob, ME Khan. 2008. Creating the conditions for scaling up the integration of reproductive health services for men in health and family welfare centers in Bangladesh. FRONTIERS Final Report. Washington, DC: Population Council.

Martines, J, VK Paul, ZA Bhutta, M Koblinsky, A Soucat, N Walker, R Bahl, H Fogstad, A Costello, Lancet Neonatal Survival Steering Team. 2005. Neonatal survival: A call to action. Lancet, 365(9465): 1189-97.

Matteelli, A, G Carosi. 2000. "STD Control in PHC Settings," in Sexually Transmitted Diseases in the Tropics. G Carosi, E Nunzi, P Fiallo, A Matteelli (Eds.). Bologna, Italy: AIFO/Italy. Accessed at <http://www.aifo.it/english/resources/online/books/other/std/contents.htm>.

Mayhew, SH, L Lush, J Cleland, G Walt. 2000. Implementing the integration of component services for reproductive health. Studies in Family Planning, 31(2): 151-162. 
Mayhew, Susannah. 2003. Impact of decentralization on SRH services in Ghana. Reproductive Health Matters, 11(21): 74-87.

McIntyre, D, B Klugman. 2003. The human face of decentralization: Experience of South Africa. Reproductive Health Matters, 11(21): 108-119.

Medina, R, Ricardo Vernon, Irma Mendoza, Claudia Aguilar. 2001. Expansion of postpartum/ postabortion contraception in Honduras. FRONTIERS Final Report. Washington, DC: Population Council.

Mohamed SA, MA Kamal, OM Shaaban, HT Salem. 2003. Acceptability for the use of postpartum interuterine contraceptive devices: Assiut experience. Medical Principles and Practice, 12(3) 170175.

Moss, William, Gary Darmstadt, David Marsh, Robert E Black, Mathuram Santosham. 2002. Research priorities for the reduction of perinatal and neonatal morbidity and mortality in developing country communities. Journal of Perinatology, 22: 484-495.

Moys, A. 2002a. District STI Quality of Care Assessment (DISCA) tool. Durban, South Africa: Health Systems Trust.

-----. 2002b. Evaluating quality of STI management at a regional level using the District Quality of Care Assessment Tool (DISCA). Durban, South Africa: Health Systems Trust.

Mphuru, Lucy, Mark Barone, Paul Perchal, and Grace Lusiola. 2006. "Integration of voluntary counseling and testing for HIV into family planning and reproductive health services in Arusha Region, Tanzania," presented at Linking Reproductive Health, Family Planning and HIV/AIDS in Africa, Addis Ababa, 9-10 October.

Mukaire, J, F Kalikwani, BN Maggwa. 1997. Integration of STI and HIV/AIDS with MCH-FP services: A case study of Busoga Diocese Family Life Education Program, Uganda. Africa Operations Research Technical Assistance Project II. Washington, DC: Population Council.

Mullick, S, D Watson-Jones, M Beksinska, D Mabey. 2005. Sexually transmitted infections in pregnancy: Prevalence, impact on pregnancy outcomes, and approach to treatment in developing countries. Sexually Transmitted Infections, 81: 294-302.

Mullick S, W Liambila, I Askew, M Menziwa, D Khoza, L Raney, L Bruce. 2008. The Balanced Counseling Strategy Plus: A toolkit for family planning service providers working in high HIV/STI prevalence settings. FRONTIERS Manual. Washington, DC: Population Council.

Murthy, RK, B Klugman. 2004. Service accountability and community participation in the context of health sector reforms in Asia: Implications for SRH services. Health Policy and Planning, 19 (suppl.): i78-i86. 
Mutahara, M, MM Rahman, A Sabir. 2009. Creating a space for men and youth at Health and Family Welfare Centers in Bangladesh. Dhaka: Population Council.

Mwangi, A, C Warren. 2008. Taking critical services to the home: Scaling up home-based maternal and postnatal care, including family planning through community midwifery in Kenya. FRONTIERS Final Report. Washington, DC: Population Council.

Mwangi, A, C Warren, N Koskei, H Blanchard. 2008. Postnatal care services including postpartum family planning in Kenya. FRONTIERS Final Report. Washington, DC: Population Council.

National AIDS and STD Control Program (NASCOP). 2009. Revitalizing the national STI/RTI control activities in Kenya: Report of a high level consultative meeting, October 14-15 2009, Nairobi. Wilson Liambila, Christine Awuor, Alice Natecho and Daniel Sande (Eds.). Nairobi: NASCOP.

National AIDS Control Organization (NACO). 2007. Operational Guidelines for Program Managers and Service Providers for Strengthening STI/RTI Services. Government of India. New Delhi: NACO.

Ndwiga, Charity. 2009. Personal Communication. Program Officer, Population Council Kenya. December 4, 2009.

Neukom, Josselyn, Jully Chilambwe. 2009. "An innovative approach to increasing uptake of long-term family planning methods in Zambia," presented at International Conference on Family Planning Research and Best Practices, Kampala, Uganda, 15-18 November.

Norton, M. 2005. New evidence on birth spacing: Promising findings for improving newborn, infant, child and maternal health. International Journal of Gynecology and Obstetrics, 89: 1-9.

Oliff, M, P Mayaud, R Brugha, AM Semakafu. 2003. Integrating reproductive health services in a reforming health sector: The case of Tanzania. Reproductive Health Matters, 11(21): 37-48.

Onyango, MA, S Owoko, M Oguttu. 2009. Male involvement in reproductive health: Strategies for male involvement in reproductive health in western Kenya: A qualitative study. Kisumu Medical Education and Trust.

O’Reilly, KR, KL Dehne, R Snow. 1999. Should management of sexually transmitted infections be integrated into family planning services: Evidence and challenges. Reproductive Health Matters, 7(14): 49-59.

Pachauri, S. 1995. "Defining an essential package of reproductive and child health services" in India's Family Welfare Program: Towards a Reproductive and Child Health Approach. Population and Human Resources, Operations Division, South Asia Country. Washington, DC: World Bank.

The Partnership for Maternal, Newborn and Child Health. 2006. Opportunities for Africa's newborns: Practical data, policy and programmatic support for newborn care in Africa. Joy Lawn and Kate Kerber (Eds.). Cape Town: WHO on behalf of The Partnership for Maternal Newborn and Child Health. 
POLICY Project/Futures Group. 2007. Inequalities in the use of family planning and reproductive health services: Implications for policies and programs. Washington, DC: Constella Futures, Health Policy Initiative, United States Agency for International Development (USAID).

Population Council. 1998. "Integration RTI services with primary health care," Update No. 9. Asia \& Near East Operations Research and Technical Assistance. Washington, DC: Population Council.

Population Council. 2008a. "Meeting the family planning needs of postpartum women," FRONTIERS Program Brief No.10. Washington, DC: Population Council.

Population Council. 2008b. "Promoting family planning during the postpartum period can increase contraceptive acceptance in Dominican Republic, Haiti and Nicaragua," FRONTIERS Integration Operations Research Summary No.74. Washington, DC: Population Council.

Population Reference Bureau (PRB). 1994. Brazil: HIV/STD prevention and family planning. Washington, DC: PRB.

Program for Appropriate Technology in Health (PATH). 1999. "A tool to assess program capacity: Adding services to manage reproductive tract infections," Reproductive Health Reports No. 3. Seattle: PATH.

RamaRao, S, J Townsend, ME Khan. 1996. A model of costs of RTI case management services in Uttar Pradesh. Asia \& Near East Operations Research and Technical Assistance Project. New Delhi: Population Council.

Ravindran, Sundari, Helen de Pinho (Eds.). 2005. The right reforms? Health sector reforms and sexual and reproductive health women's health project. South Africa: School of Public Health, University of Witwatersrand.

Reproductive Health Research Unit (RHRU). 2000. Antenatal syphilis screening and management procedures in South Africa. Durban, South Africa: Press Gang.

Reproductive Health Research Unit (RHRU), Initiative for Sub-District Support (ISDS). 2001. Evaluating the quality of care for sexually transmitted infections: Using DISCA (District STI Clinic Assessment). Durban: Health Systems Trust and Reproductive Health Research Unit.

Republic of Kenya, Ministry of Health (MOH). 2007. Monthly supervision and monitoring tool for integrating STIs/RTIs into reproductive health settings. Nairobi: MOH Kenya.

Richey, C, RM Salem. 2008. "Elements of success in family planning programming", Population Reports Series J, No. 57. Baltimore: INFO Project/John Hopkins Bloomberg School of Public Health Center of Communication Programs.

Rivero-Fuentes, M Estela, Saumya Ramarao, Ricardo Estrada, Charlotte Warren, Saiqa Mullick, Harriet Birungi, Ian Askew, John Townsend, Susana Medina. 2008a. Assessing Integration 
Methodology (AIM): A handbook for measuring and assessing the integration of family planning and other reproductive health services. Washington, DC: Population Council.

Rivero-Fuentes, M Estela, Ricardo Vernon, Michelle Boulos, Louis-Marie Boulos. 2008b. Situation analysis of the integration of family planning services in postpartum, postabortion and prevention of mother to child transmission programs in Haiti. FRONTIERS Final Report. Washington, DC: Population Council.

Rivero-Fuentes, M. Estela, Ricardo Vernon. 2008. The effect of access to family planning services during antenatal, delivery and postpartum care on contraceptive use in the postpartum period. FRONTIERS Final Report. Washington, DC: Population Council.

Rob, Ubaidur. 2009. Personal communication. Senior Associate and Country Director, Bangladesh, Population Council. November 10, 2009.

Rob, Ubaidur. 2010. Personal communication. Senior Associate and Country Director, Bangladesh, Population Council. January 5, 2010.

Rob, Ubaidur, Sharif Mohammed Ismail Hossain, Ismat Bhuiya. 2002. "Integration of reproductive health services for men in family welfare centers," FRONTIERS Research Update No. 1. Dhaka: Population Council.

Ross, J, W Winfrey. 2001. Contraceptive use, intention to use and unmet need during the extended postpartum period. International Family Planning Perspectives, 27(1):20-27.

Rutenberg, N, C Baek. 2005. A review of program experience with integrating family planning into prevention of mother-to-child transmission programs. Studies in Family Planning, 36(3): 235245.

Sanders, Rachel, Scott Moreland, Thomas Goliber. 2009. "Achieving the MDGs: The contribution of family planning," presented at International Conference on Family Planning Research and Best Practices, Kampala, Uganda, 15-18 November.

Santhya, KG, SJ Jejeebhoy, S Ghosh. 2007. Addressing the sexual and reproductive health needs of young people: Perspectives and experiences of stakeholders from the health and non-health sectors. Delhi: Population Council.

Schierhout, S, SA Fonn. 1999. The integration of primary health care services: A systematic literature review. Health Systems Trust, South Africa.

Schmid, G. 2004. Economic and programmatic aspects of congenital syphilis prevention. Bulletin of the World Health Organization. 82: 402-409

Singh, S, JE Darroch, LS Ashford, M Vlassof. 2009. Adding it up: The costs and benefits of investing in family planning and maternal and newborn health. New York: The Guttmacher Institute/UNFPA. 
Singh, S, JE Darroch, M Vlassof, J Nadeau. 2003. Adding it up: The benefits of investing in sexual and reproductive health care. New York: The Guttmacher Institute.

Sloan, NL, B Winicoff, N Haberland, C Coggins, C Elias. 2000. Screening and syndromic approaches to identify gonorrhea and chlamydial infection among women. Studies in Family Planning, 31(1): $55-68$.

Smith, KB, ZM van der Spuy, L Cheng, R Elton, AF Glasier. 2002. Is postpartum contraceptive advice given antenatally of value? Contraception, 65(3): 237-243.

Soliman, MH. 1999. Impact of antenatal counseling on couples' knowledge and practice in Mansoura Egypt. East Mediterranean Health Journal, 5(5): 1002-1013.

Spensley, A, T Sripipatana, AN Turner, C Hoblitzelle, J Robinson, C Wilfert. 2009. Preventing mother-tochild transmission of HIV in resource-limited settings: The Elizabeth Glaser Pediatric AIDS Foundation Experience. American Journal of Public Health, 99: 631-63.

Speroff, L, DR Mishell. 2008. The postpartum visit: It's time for a change in order to optimally initiate contraception. Contraception, 78(2): 90-8.

Stephenson, P, F Donnay, O Frolova, et al. 1998. “Improving women's health in the Russian Federation: Results of a pilot project," Technical Paper No. 404. Washington, DC: World Bank.

Talukder, MN, U Rob, MM Rahman. 2009. Improving the quality of family planning and reproductive tract infection services for urban slum populations: Demand-based reproductive health commodity project. Dhaka, Bangladesh: Population Council.

Teffo- Menziwa, Mantshi. 2010. Personal Communication. Senior Reproductive Health Program Officer, Population Council South Africa. January 6, 2010.

The African Union Commission. n.d. Maputo plan of cction: For implementing the continental sexual and reproductive health and rights policy framework 2007-2010.

The Alan Guttmacher Institute. 2002. "Family Planning Can Reduce High Infant Mortality Levels," Issues in Brief: Series 2. New York and Washington: The Guttmacher Institute.

-----. 2004. "Adolescents in Burkina Faso: Sexual and Reproductive Health," Research in Brief Series, No.3. New York and Washington, DC: The Guttmacher Institute.

-----. 2007. "Facts about the unmet need for contraception in developing countries," In Brief Series, New York and Washington: The Guttmacher Institute.

Thompson, A, B Janowitz, J Solo. 1999. The cost of health services at the facilities level of the Nakuru Municipal Council, Nakuru, Kenya. Africa Operations Research Technical Assistance Project II. Nairobi: Population Council. 
Tilley Ian B, Omar M Shabaan, Melissa Wilson, Anna Glasier, Daniel R Mishell. 2009. Breastfeeding and contraception use among women with unplanned pregnancies less than two years after delivery. International Journal of Gynecology and Obstetrics, 105: 127-130.

Turan JM, H Nalbant, A Bulut, Y Sahip. 2001. Including expectant fathers in antenatal education programs in Istanbul, Turkey. Reproductive Health Matters, 9(18): 114-125.

Twahir, A, BN Maggwa, I Askew. 1996. Integration of STI and HIV/AIDS services with MCH-FP services: A case study of Mkomani Clinic Society in Mombasa, Kenya. Africa Operations Research Technical Assistance Project II. Washington, DC: Population Council.

UK All Party Parliamentary Group on Population, Development and Reproductive Health. 2009. Better off dead? A report on maternal morbidity from UK All Party Parliamentary Group on Population, Development and Reproductive Health. London: UK All Party Parliament Group on Population, Development and Reproductive Health.

United Nations Children's Fund (UNICEF). 2009. The state of the world's children: Maternal and newborn health. New York: UNICEF.

United Nations Population Fund (UNFPA). 1994. ICPD Program of Action. Accessed at $<$ http://www.unfpa.org/publications/detail.cfm?ID=275>.

-----. 1999. "Implementing RH Vision - Progress and future challenges for UNFPA," Evaluation Findings Issue 28. New York: UNFPA, Office of Oversight and Evaluation.

-----. 2004a. "The New York call to commitment: Linking HIV/AIDS and sexual and reproductive health." New York: UNFPA.

-----. 2004b. Sexually transmitted infections: Breaking the cycle of transmission. New York: UNFPA.

-----. 2005a. Investing in People: National progress in implementing ICPD Program of Action 1994 2004. New York: UNFPA.

-----. 2005b. A global need for FP link to UNFPA fact sheets. New York: UNFPA. Accessed at <http://www.unfpa.org/rh/planning/mediakit/docs/new_docs/sheet1-english.pdf>.

-----. 2008. Contraceptives save lives: Women are dying every day. Family Planning Resource Kit. New York: UNFPA. Accessed at <http://www.unfpa.org/rh/planning/mediakit/>.

-----. 2009. Reproductive health: Breaking the cycle of transmission. New York: UNFPA. Accessed December 1, 2009 at <http://www.unfpa.org/rh/stis.htm>.

United Nations Population Fund (UNFPA), International Planned Parenthood Federation (IPPF). 2004. Integrating HIV voluntary counseling and testing services into reproductive health services: Stepwise guidelines for program planners, managers and service providers. UK: IPPF South Asia Regional Office; New York: UNFPA. 
United Nations (UN) Statistics Division. 2008. Millennium Development Goals monitoring framework: official list of MDG indicators. New York: UN. Accessed at <http://mdgs.un.org/unsd/mdg/Resources/Attach/Indicators/OfficialList2008.pdf>.

United States Agency for International Development (USAID). 2005. "Takamol Integrated Reproductive Health Services Project," Activity Brief. Cairo: USAID-Egypt.

Vartapetova, Natalia V, Anna V Karpushkina. 2006. "Prevention of Mother-to-Child Transmission of HIV and Family Planning Practices in HIV-Infected Women," Maternal and Child Health Initiative 2. Moscow: John Snow Inc.

Vernon Ricardo, Jorge Solórzano, Blanca Muñoz. 2007. Introducing sustainable vasectomy services in Guatemala. International Family Planning Perspectives, 33(4): 182-187.

Vernon, Ricardo, James R Foreit, Emma Ottolenghi. 2008. Introducing systematic screening to reduce unmet health needs: A manager's manual. FRONTIERS Manual, revised edition. Washington, DC: Population Council.

Wabaru, James Kariba, Bedan Kiarie Kariuki, Baker Ndugga Maggwa. 1997. Integration of STI and HIV/AIDS with MCH-FP Services: A case study of the Nakuru Municipal Council's project on strengthening STD/AIDS control. Africa Operations Research Technical Assistance Project II. Nairobi: Population Council.

Wallace A, V Dietz, KL Cairns. 2009. Integration of immunization services with other health interventions in the developing world: What works and why? Tropical Medicine \& International Health, 14(1):11-9.

Waller, Maureen R, Marianne P Bitler. 2008. The link between couples' pregnancy intentions and behavior: Does it matter who is asked? Perspectives on Sexual and Reproductive Health, 40(4): 194-201.

Warren Charlotte, Wilson Liambila. 2004. Safe motherhood demonstration project Western Province: approaches to providing quality maternal care in Kenya. Final Report. Nairobi: Population Council, Republic of Kenya Ministry of Health, University of Nairobi.

Warren C, P Daly, L Touré, P Mongi. 2006. “Postnatal Care Opportunities for Africa's Newborns”, in Opportunities for Africa's newborns: Practical data, policy and programmatic support for newborn care. J. Lawn and K. Kerber (Eds.) Cape Town, South Africa: Africa Partnership for Maternal, Newborn and Child Health.

Warren C, R Shongwe, Allen Waligo, Mohammed Mahdi, Goldy Mazia, Indira Narayanan. 2008a. Repositioning postnatal care in a high HIV environment: Swaziland. HORIZONS Final Report. Washington, DC: Population Council. 
Warren C, T Ts'ukulu, P Semakaleng, M Bosielo. 2008b. Extending prevention of mother-to-child transmission through postpartum family planning in Lesotho. FRONTIERS Final Report. Washington, DC: Population Council.

Warren, Charlotte, Annie Mwangi, Erick Oweya, Rosemary Kamunya and Nancy Koskei. 2009. Safeguarding maternal and newborn health: improving the quality of postnatal care in Kenya. International Journal for Quality in Health Care, 22(1): 24-30.

World Health Organization (WHO). 1994. Management of Sexually Transmitted Diseases. GPA/TEM/94.1, Geneva: WHO/Global Program on AIDS (GPA).

-----. 2003. Guidelines for the management of sexually transmitted infections. Geneva: WHO.

-----. 2004. Reproductive health strategy to accelerate progress towards the attainment of international development goals and targets. Geneva: WHO/Department of Reproductive Health and Research (RHR).

-----. 2005. Sexually transmitted and other reproductive tract infections: A guide to essential practices. Geneva: WHO/Reproductive Health and Research (RHR).

-----. 2006. The Lancet: Executive summary. Lancet Sexual and Reproductive Health Series. Family Care International.

-----. 2007a. Everybody's business: Strengthening health systems to improve health outcomes. Framework for Action. Geneva: WHO.

-----. 2007b. Global strategy for the prevention and control of sexually transmitted infections: 20062015: Breaking the chain of transmission. Geneva: WHO.

-----. 2007c. The global elimination of congenital syphilis: Rationale and strategy for action. Geneva: WHO.

-----. 2008a. Asia-Pacific operational framework for linking HIV/STI services with reproductive, adolescent, maternal, newborn and child health services. Geneva: WHO Western Pacific Region.

-----. 2008b. Primary health care: Now more than ever. The World Health Report, 2008. Geneva: WHO.

-----. 2008c. Expert group meeting for prevalence survey on selected STIs in MCH/FP settings. Delhi: WHO Regional Office for South-East Asia.

-----. 2009. Recommended interventions for improving maternal and newborn health: Integrated management of pregnancy and childbirth. Second Edition. Geneva: WHO/Department of Making Pregnancy Safer. 
World Health Organization (WHO), The Joint United Nations Program on HIV/AIDS (UNAIDS). 1999. Sexually transmitted diseases: Policies and principles for prevention and care. WHO/UNAIDS Best Practice Collection. Geneva: WHO/UNAIDS.

World Health Organization (WHO), International Planned Parenthood Federation (IPPF), The Joint UN Program on HIV/AIDS (UNAIDS), United Nations Population Fund (UNFPA). 2005. Sexual and reproductive health \& HIV/AIDS: A framework for priority linkages. Geneva: WHO.

World Health Organization (WHO), International Planned Parenthood Federation (IPPF), The Joint UN Program on HIV/AIDS (UNAIDS), United Nations Population Fund (UNFPA), University of California. 2009. Sexual \& reproductive health and HIV linkages: Evidence review and recommendations. Geneva: WHO.

World Health Organization (WHO), Population Council. 2009. A strategic approach to strengthening control of reproductive tract and sexually transmitted infections: Use of the program guidance tool. Geneva: WHO.

World Health Organization (WHO), United Nations Population Fund (UNFPA). 2004. Glion Call to Action on Family Planning and HIV/AIDS in Women and Children. 3-5 May.

World Health Organization Department of Reproductive Health and Research (WHO/RHR), Johns Hopkins Bloomberg School of Public Health/Centre for Communication Programs (JHUCCP). 2008. Family Planning: A Global Handbook for Providers (2008 update) Baltimore and Geneva: WHO and JHUCCP.

Workowski KA, SM Berman. 2006. Sexually transmitted diseases treatment guidelines. MMWR Recommendations and Report, 22:1-94.

Yeboah, David. 2005. Strategies adopted by Caribbean family planning associations to address declining international funding. International Family Planning Perspectives, 28 (2): 122-25.

Zerai, A, AO Tsui. 2001. The relationship between antenatal care and subsequent modern contraceptive use in Bolivia, Egypt and Thailand. African Journal of Reproductive Health, 5(2): 68-82. 